\title{
The causes, consequences, and treatment of left or right heart failure
}

\author{
This article was published in the following Dove Press journal: \\ Vascular Health and Risk Management \\ 7 April 201 I \\ Number of times this article has been viewed
}

\section{Pablo Pazos-López \\ Jesús Peteiro-Vázquez \\ Ana Carcía-Campos \\ Lourdes García-Bueno \\ Juan Pablo Abugattas \\ de Torres \\ Alfonso Castro-Beiras}

Department of Cardiology, Complejo hospitalario Universitario A Coruña,

A Coruña, Spain
Correspondence: Pablo Pazos-López Juan Bautista Andrade $644^{\circ}$, C.P. 36005 , Pontevedra, Spain

Tel +34 6I 9907556

Fax +34 98 II 78258

Email pablo.pazos.lopez@gmail.com

\begin{abstract}
Chronic heart failure (HF) is a cardiovascular disease of cardinal importance because of several factors: a) an increasing occurrence due to the aging of the population, primary and secondary prevention of cardiovascular events, and modern advances in therapy, b) a bad prognosis: around $65 \%$ of patients are dead within 5 years of diagnosis, c) a high economic cost: HF accounts for $1 \%$ to $2 \%$ of total health care expenditure. This review focuses on the main causes, consequences in terms of morbidity, mortality and costs and treatment of HF.
\end{abstract}

Keywords: heart failure, cause, consequence, treatment

\section{Definition, classification, and occurrence of heart failure}

Heart failure (HF) is a complex clinical syndrome caused by structural or functional cardiac disorders that impair the ability of one or both ventricles to fill with or eject blood. ${ }^{1}$ For the diagnosis of HF, symptoms (typically shortness of breath at rest or during exertion and/or fatigue), signs of fluid retention (such as pulmonary congestion and/or ankle swelling), and objective evidence of a decrease in myocardial performance at rest (normally demonstrated in an echocardiography study) are required. ${ }^{2}$ According to the time from ventricular dysfunction to clinical manifestations, left ventricular ejection fraction (LVEF), and the main site of congestion, HF can be divided into different groups (Figure 1). Generally, it is a chronic condition with bouts of worsening symptoms that may require medical attention (decompensations). However, it may present acutely within just 24 hours in the form of pulmonary edema or even cardiogenic shock. Conventionally, HF was seen to result from the failure of the heart to pump enough blood into the circulation due to ventricular systolic dysfunction defined as LVEF $<40 \%$ to $50 \%$ (HF with depressed ejection fraction [HFDEF]). ${ }^{2}$ Nevertheless, patients with nondecreased LVEF can develop HF when higher filling pressures are needed to achieve a normal end-diastolic ventricular volume (HF with preserved ejection fraction [HFPEF]). The occurrence of this condition is more common in women, in the elderly, and in persons with longstanding high blood pressure (HBP) and is associated with a similar prognosis to HFDEF., Right and left HF refer to syndromes presenting predominantly with systemic or pulmonary congestion leading to jugular venous ingurgitation and ankle swelling or pulmonary edema, respectively.

Generally speaking, the prevalence of HF can be estimated at $1 \%$ to $2 \%$ in Western countries and the incidence approaches 5 to 10 per 1000 persons per year. Data on the occurrence of HF in the developing world are largely absent. This high prevalence is 

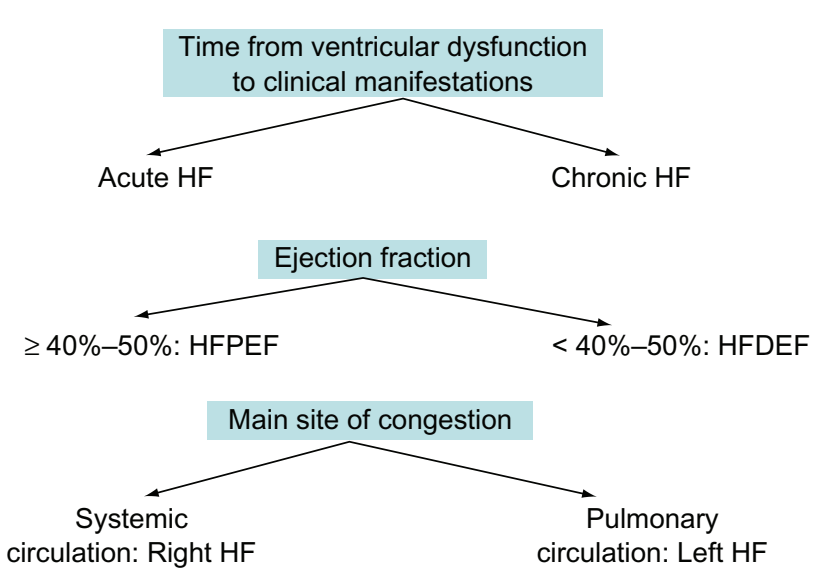

Figure I Types of heart failure.

Abbreviations: HF, heart failure; HFDEF, heart failure with depressed ejection fraction; HFPEF, heart failure with preserved ejection faction.

increasing because of the aging population, the success in primary and secondary prevention of coronary events, and the development of modern treatments. The mean age of patients with $\mathrm{HF}$ in industrialized societies is approximately 75 years. $^{5}$

This review will focus on the main causes, consequences (in terms of morbidity, mortality, and economic costs), and treatment of chronic HF.

\section{Causes of HF}

Although many conditions may lead to HF, the predominant etiologies are myocardial ischemia and HBP (Table 1). The discrepancies in the frequency of causes reported in the medical literature can be explained by differences in the study population (from highly selected participants in clinical trials to relatively unselected subjects in population-based studies, respectively), definitions (eg, consensus on a cut-off value for LVEF to define HFPEF has not been reached), and time period (eg, the Framingham heart study originated in 1948). Furthermore, it has become clear that by using only noninvasive techniques, precise etiology cannot always be determined. For instance, in the Bromley HF study after nuclear testing and cardiac catheterization the percentage of HF with unknown cause declined from $42 \%$ to $10 \%$, while the

Table I Main causes of heart failure

- Myocardial ischemia

- HBP

- Cardiomyopathies

- Valvular heart disease

- PHT

- Congenital heart disease

Abbreviations: HBP, high blood pressure; PHT, pulmonary hypertension. See text for details. percentage of patients with ischemic heart disease increased from $29 \%$ to $52 \%{ }^{6}$

\section{Myocardial ischemia}

Coronary artery disease (CAD) may be the initiating cause in $\approx 70 \%$ of cases of $\mathrm{HF}^{7}$ Even in $\mathrm{HF}$ individuals clinically classified as nonischemic, evidence of ischemia has been found. Up to $25 \%$ may have significant atherosclerosis plaques in the coronary trees at autopsy, ${ }^{8}$ which points out the limited diagnostic accuracy of image techniques such as angiography. Besides, it has been reported that these patients may suffer ischemic events on the follow-up, a finding that suggests that CAD may not be just a 'bystander'. 9 Moreover, the high prevalence of a reduced flow reserve demonstrated in subjects with $\mathrm{HF}$ and nonsignificant stenosis in the main coronary arteries incriminates microvascular impairment as a potential contributor to their myocardial dysfunction. ${ }^{10,11}$

\section{Mechanisms of HF in CAD (Figure 2)}

1. Acute myocardial infarction (MI) frequently causes the death of the myocytes of one or more ventricular segments that become scarred, resulting in inadequate relaxation in diastole and impaired contraction in systole. Further decrease in ventricular performance may occur if an aneurysm is developed. MI can also predispose to HF by the dyssynchronous movement of the infarct area that can lessen the efficiency of pump function.

2. Whereas the initial myocardial scarring results in local dysfunction, remodeling in remote areas of the left ventricle (LV) may take place resulting in a distortion of the ventricular structure and geometry, which can contribute to an additional decrement of ventricular function. ${ }^{12}$ Besides, ventricular enlargement may promote dysfunction of the mitral apparatus with the consequent mitral regurgitation (MR), which can predispose to $\mathrm{HF}$.

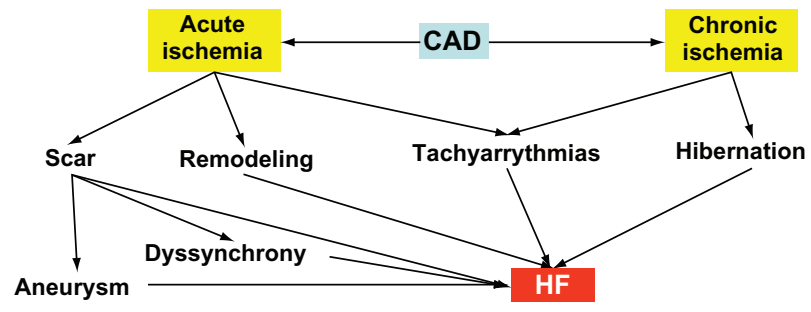

Figure 2 From coronary artery disease to heart failure. Abbreviations: CAD, coronary artery disease; HF, heart failure. 
3. Several tachyarrhythmias such as nonsustained ventricular tachycardia (NSVT) or atrial fibrillation/atrial flutter (AF), common in patients with CAD, can deteriorate cardiac function.

- Loss of atrial contraction in AF decreases ventricular filling and stroke volume.

- Systolic volume is diminished during NSVT due to atrioventricular dissociation and the consequent drop of preload.

- Diastolic time shortening, found in both arrhythmias, also contributes to the lessening of filling and cardiac output.

- When AF and NSVT are persistent they may lead to tachycardia-induced cardiomyopathy (tachycardiomyopathy). ${ }^{13}$

4. Maintained reduction in blood supply due to chronic severe coronary stenosis may result in low myocardial performance (hibernation). ${ }^{14}$

\section{HBP}

HBP boosts HF risk by two- to three-fold. ${ }^{15,16}$ Although the relative risk of developing $\mathrm{HF}$ in HBP is modest, its high prevalence renders it a cause in approximately one-third of cases. ${ }^{17}$ Besides, HBP is an independent risk factor for CAD.

\section{Effects of HBP in the heart}

In hypertensive patients, the myocardium has to pump blood against a higher afterload posed by the elevated resistance of the peripheral vasculature. This condition leads to a compensatory increase in myocardial mass in order to maintain normal cardiac output. Left ventricular hypertrophy ( $\mathrm{LVH})$ in HBP is characterized not only by enlargement of the cardiac myocytes but also by an increase of interstitial and perivascular fibrosis. ${ }^{18}$ The progression from a structurally normal heart to LVH is not solely a consequence of enhanced afterload; many mechanisms are known to be involved, particularly the renin-angiotensin-aldosterone system (RAAS). ${ }^{19}$

\section{Mechanisms of HF in HBP (Figure 3)}

1. Hypertrophic ventricles are characterized by a higher myocardial stiffness and a decreased ability to relax and fill. $^{20-23}$

2. HBP is associated with myocardial ischemia even in the absence of CAD. Three main mechanisms are implicated: ${ }^{24}$

- In HBP, the growth of the coronary bed does not keep pace with the increase in cardiac mass, proving a 'set up' for chronic ischemia.
- Coronary arteries travel across ventricular walls from the epicardium to the endocardium, perfusing the myocardium mainly during diastole due to a positive ratio between the intravessel and parietal pressures. Such a ratio is reduced in HBP as a consequence of the high ventricular chamber pressure transmitted to the walls, which promotes ischemia. This effect is more pronounced at the subendocardial level.

- Coronary flow reserve is impaired due to structural and functional changes in the arterioles (medial wall thickening and perivascular fibrosis boost vessel resistance, endothelial dysfunction impairs vasodilatation capacity).

These conditions may lead to HFPEF. Persistent work overload, hypoxia, and neurohumoral stimulation in longstanding uncontrolled HBP can promote myocyte apoptosis and eventually systolic dysfunction. ${ }^{25}$

\section{Cardiomyopathies}

According to the new classification recently published by the Working Group on Myocardial and Pericardial Diseases of the European Society of Cardiology, a cardiomyopathy is a

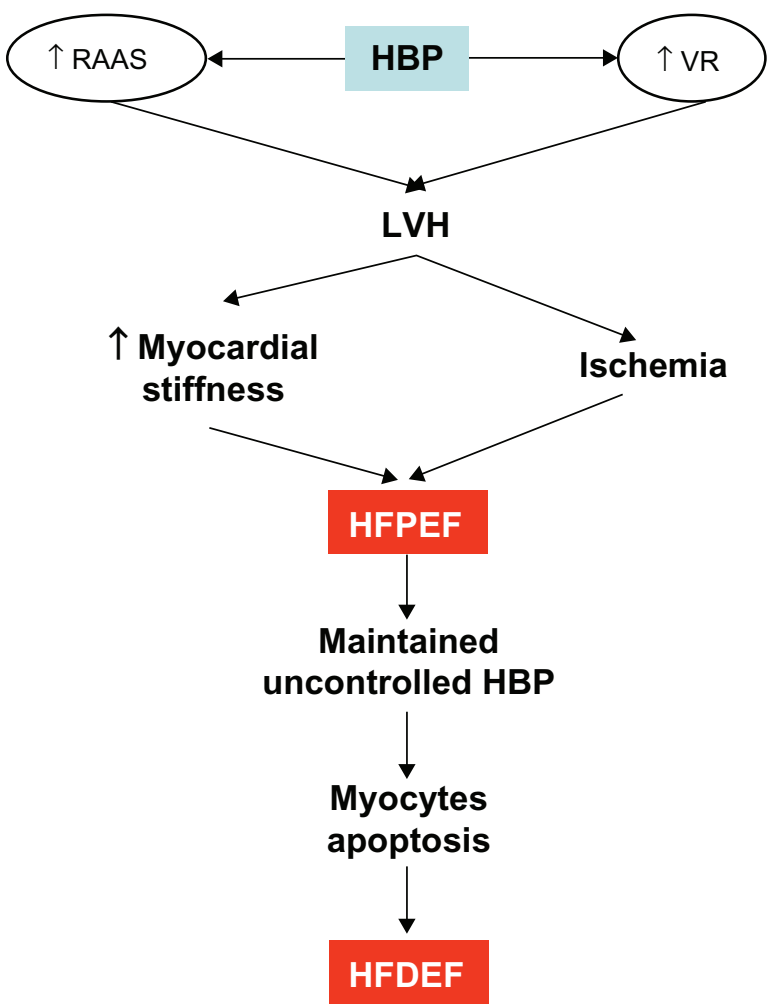

Figure 3 From high blood pressure to heart failure.

Abbreviations: HBP, high blood pressure; HFDEF, heart failure with depressed ejection fraction; HFPEF, heart failure with preserved ejection fraction; LVH, left ventricular hypertrophy; RAAS, renin-angiotensin-aldosterone system; VR, vascular resistance. 
myocardial disorder in which the heart muscle is structurally and functionally abnormal in the absence of CAD, HBP, valvular, or congenital heart disease severe enough to cause the observed myocardial abnormality. Cardiomyopathies are grouped into five specific phenotypes: dilated cardiomyopathy (DCM), hypertrophic cardiomyopathy (HCM), restrictive cardiomyopathy (RCM), arrhythmogenic right ventricular cardiomyopathy (ARVC), and other unclassified cardiomyopathies (isolated noncompaction of the left ventricle [INLV] and Takotsubo syndrome are included in this category). Each phenotype is subclassified into familial and nonfamilial forms taking into account the presence or absence in more than one member of the family, of either the same disorder or a phenotype that is (or could be) caused by the same genetic mutation. Nonfamilial cardiomyopathies are divided into idiopathic (when no identifiable cause is found) or acquired forms (in which ventricular dysfunction is a complication of the disorder rather than an intrinsic feature of the disease). ${ }^{26}$

\section{DCM}

This entity is much more common by far than the other major types of cardiomyopathies. DCM is a heterogeneous disease characterized by left ventricular and sometimes atrial dilation (right ventricular enlargement and dysfunction may be present but is not necessary for the diagnosis), with normal or reduced wall thickness eventually leading to varying degrees of impaired systolic function. The clinical picture at the time of diagnosis can vary widely from patient to patient; some have no symptoms, whereas others develop a progressive refractory HF. When the etiology is investigated with specialized techniques, at least $25 \%$ of patients have evidence of familial disease with predominantly autosomal dominant inheritance. ${ }^{27,28}$ Frequent nonfamilial acquired causes of DCM include cardiotoxic drugs such as anthracyclines, alcohol, or cocaine, late stage of cardiac infectious and inflammatory diseases (myocarditis), and persistent tachyarrhythmias (tachycardiomyopathy) (Table 2).

\section{HCM}

The new classification has redefined HCM as the presence of an increased ventricular wall thickness or mass in the absence of loading conditions (HBP, valve disease) sufficient to cause the observed abnormality. ${ }^{26}$ Following this new definition, those diseases in which ventricular mass is increased due to interstitial infiltration or intracellular accumulation of metabolic substrates are included in this category (Table 3 ).

LVH in the absence of HBP and valve disease occurs in approximately 1 in 500 of the general population.
Table 2 Causes of dilated cardiomyopathy

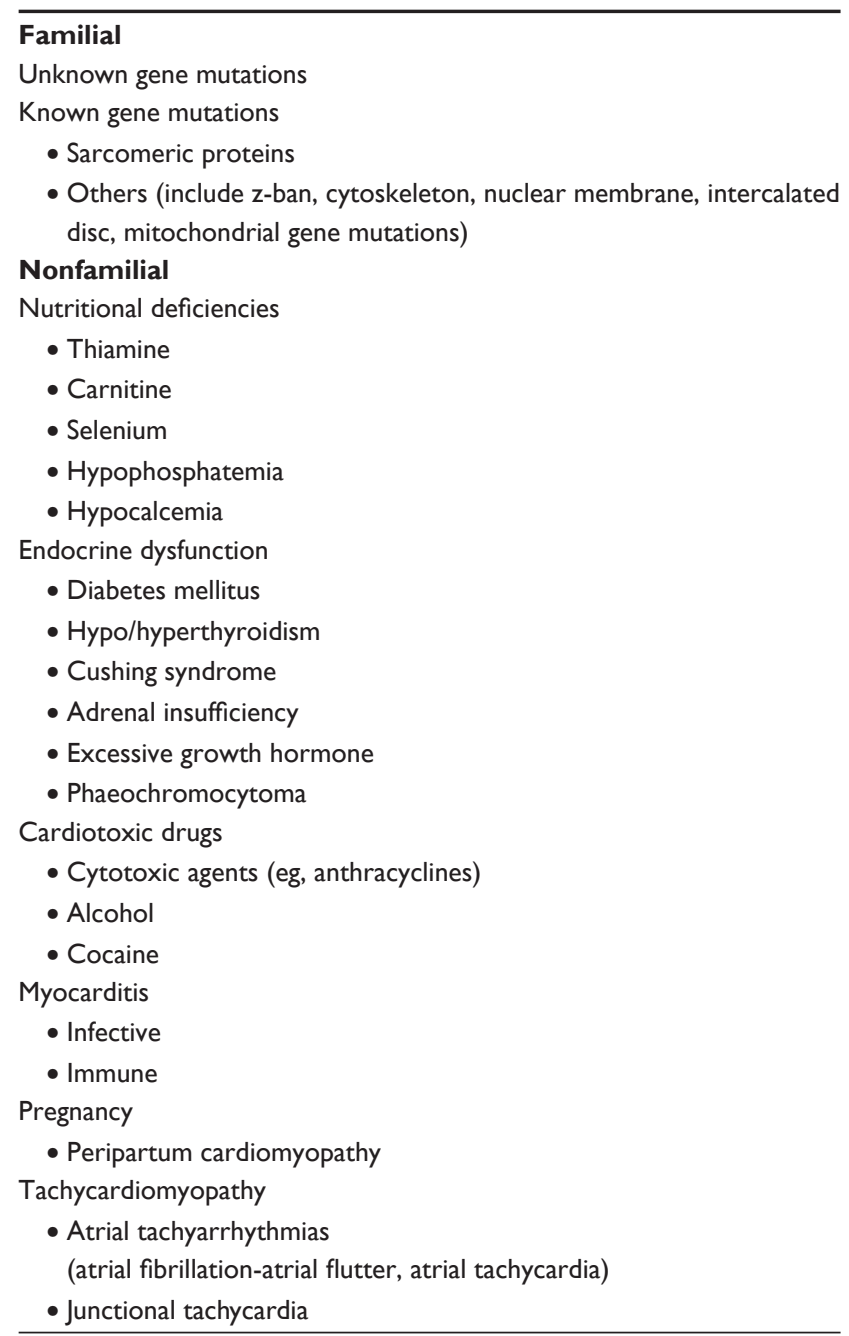

Many individuals have a familial disease with an autosomal dominant pattern of inheritance. Mutations identified in these patients affect genes that encode different proteins of the cardiac sarcomere. HCM caused by such mutations predominantly has an asymmetrical pattern of $\mathrm{LVH}$, the interventricular septum segments being the most frequently affected, and myocyte disarray. ${ }^{29} \mathrm{LV}$ volume is usually small and LVEF preserved. Symptoms are related to an impaired ventricular filling (HFPEF), and in some cases, to left outflow track dynamic obstruction. Progression to LV dilatation and systolic dysfunction is rare (from $2.5 \%$ up to $15 \%$ in some series). ${ }^{30}$

Although all types of LVH may be present in sarcomeric protein disease, concentric forms are more common in metabolic disorders (eg, Anderson-Fabry disease). Other differential features that may help in the diagnosis of these entities are the inheritance pattern (X-linked, autosomal recessive) and the presence of signs and symptoms derived from multisystemic affectation. ${ }^{26}$ 
Table 3 Causes of hypertrophic cardiomyopathy

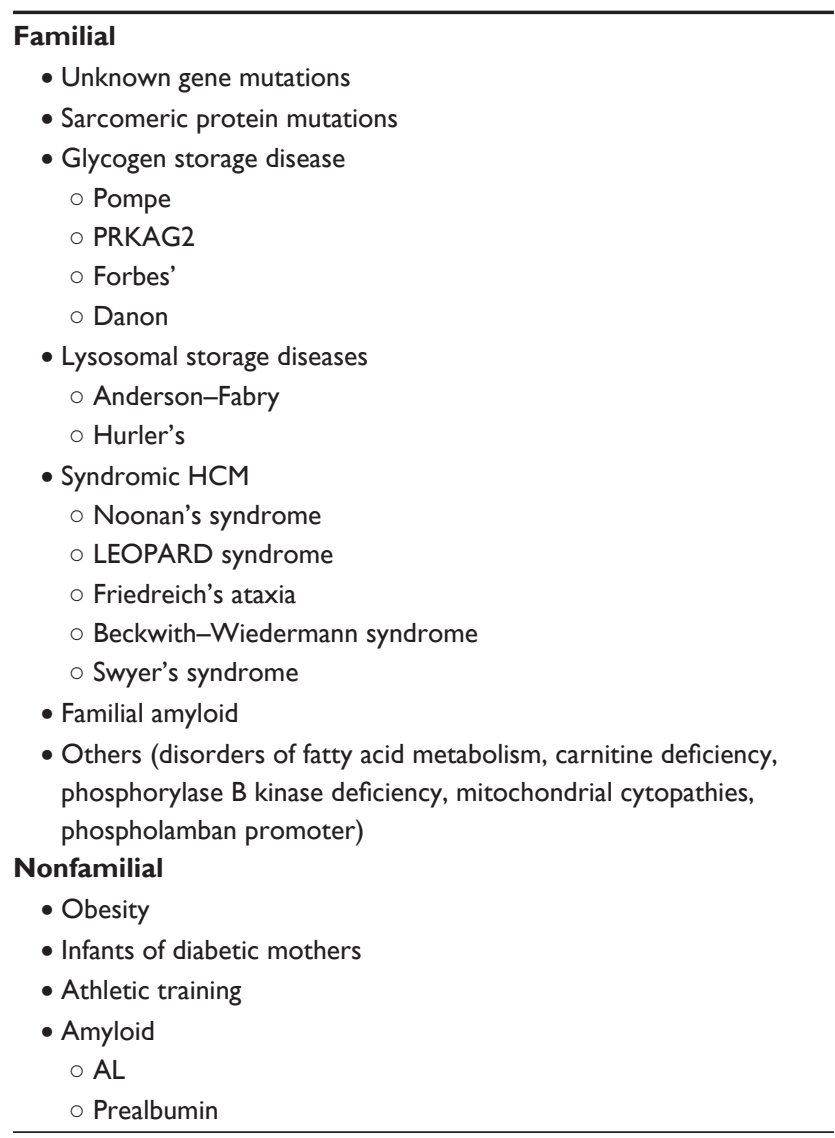

Abbreviations: AL, amyloidosis; HCM, hypertrophic cardiomyopathy.

Athletic training is associated with physiological LVH that can be misinterpreted as a pathological phenotype, but the degree of wall thickness is much less pronounced $(<13 \mathrm{~mm}$ in septal segments in most cases) and diastolic function is normal. ${ }^{31}$

\section{RCM}

This cardiomyopathy is characterized by a severe diastolic dysfunction (restrictive physiology) in the presence of normal or reduced diastolic volumes (of one or both ventricles), normal or reduced systolic volumes, and normal ventricular wall thickness. Although historically, systolic function has been said to be preserved in RCM, contractility is not completely normal in this entity. ${ }^{26}$ Although the exact prevalence of RCM is unknown it is probably the least prevalent type of cardiomyopathy. RCM may be idiopathic, familial, or result from various systemic disorders (Table 4). As can be seen from comparing Tables 3 and 4, several genetic mutations and infiltrative diseases may present with a restrictive or hypertrophic phenotype.

\section{ARVC}

Ventricular arrhythmias and sudden cardiac death (SCD) are the main manifestations of this rare cardiomyopathy
Table 4 Causes of restrictive cardiomyopathy

\begin{tabular}{l}
\hline Familial \\
- Unknown gene \\
- Sarcomeric protein mutations \\
- Familial amyloidosis \\
○ Transthyretin (RCM + neuropathy) \\
$\circ$ Apolipoprotein (RCM + nephropathy) \\
- Anderson-Fabry disease \\
- Glycogen storage diseases \\
- Hemochromatosis \\
- Ohers (desminopathy, pseuxanthoma elasticum) \\
Nonfamilial \\
- Amyloid \\
○ AL \\
○ prealbumin \\
- Scleroderma \\
- Endomyocardial fibrosis \\
○ Hypereosinophilic syndrome \\
○ Idiopathic \\
○ Chromosomal cause \\
○ Drugs (serotonin, methysergide, ergotamine, mercurial agents, \\
busulfan) \\
- Carcinoid heart disease \\
- Retastatic cancers \\
\hline Abbreviations: AL, amyloidosis; RCM, restrictive cardiomyopathy. \\
Drugs (anthracyclines)
\end{tabular}

(1/1000-5000). Although uncommon, right ventricular or biventricular HF mimicking a DCM may be present. ${ }^{32}$

\section{INLV}

INLV is an infrequent unclassified cardiomyopathy $(0.014 \%$ of consecutive echocardiograms) assumed to occur due to an arrest in the compaction process of the LV during the normal development of the heart. This entity is morphologically characterized by the appearance of prominent trabeculations and deep intertrabecular recesses mainly in the apex and in the inferior and lateral mid segments, with an endsystolic ratio between the noncompacted subendocardial layer and the compacted subepicardial layer $>2$. The clinical presentation of INLV includes a high prevalence of $\mathrm{HF}$, thromboembolic events and arrhythmias including ventricular tachycardia and $\mathrm{AF}^{33}$ INLV is commonly familial, with at least $25 \%$ of asymptomatic relatives having a range of echocardiographic abnormalities. ${ }^{34}$ Causative mutations in several genes have been identified. ${ }^{26}$

\section{Valvulopathies}

A severe increase in ventricular afterload may lead to HF in severe aortic and pulmonary stenosis. In valve regurgitation, a persistent volume overload may cause ventricular enlargement and functional impairment. 


\section{Other causes of HF}

The elevated resistance of the pulmonary vasculature in pulmonary hypertension may promote right HF. A special case of this condition is observed in patients with chronic obstructive pulmonary disease (cor pulmonale).

Congenital heart diseases such as interventricular and interatrial communication or persistent arterial ductus can lead to HF due to maintained volume overload.

\section{Consequences of HF}

\section{Reduction of functional capacity}

Functional capacity in HF patients is limited by shortness of breath and fatigue on exertion. A basic pathophysiology of these symptoms can be summarized in two points (Figure 4):

1. When diastolic dysfunction is developed the failing heart requires a higher LV filling pressure to maintain output, particularly during exertion. The filling pressure of the LV can become high enough to cause stiff lungs or even transudation of fluid into the alveoli leading to breathlessness.

2. If systolic function is impaired, the failing heart may be unable to increase the stroke volume adequately in response to exercise. In turn, this leads to the inability to perfuse the exercising muscle effectively. The affected skeletal muscle signals the brain, and this sensation is interpreted as fatigue.

Although this view regards HF as a hemodynamic disorder, many studies have indicated that measurements of cardiac performance and symptoms produced by the disease are

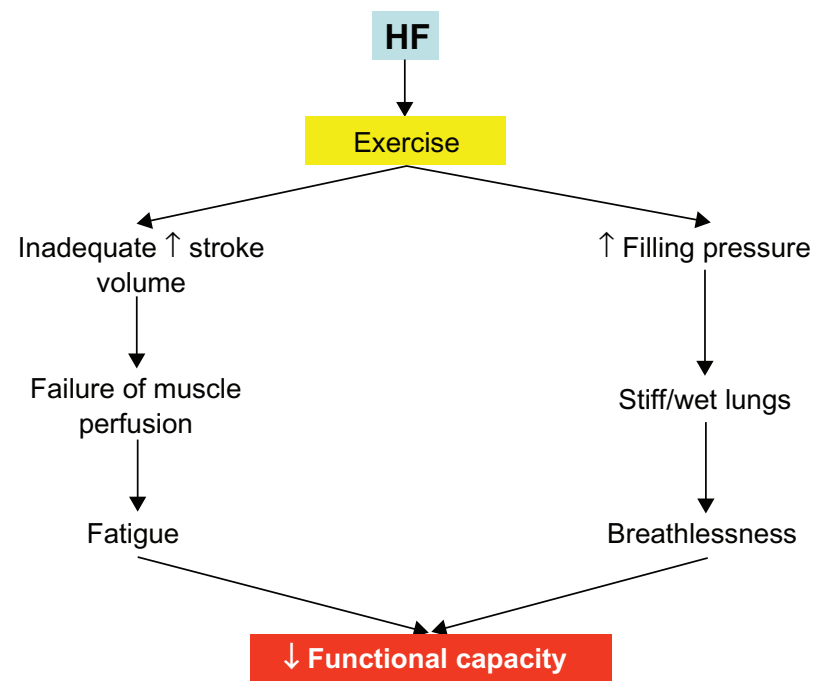

Figure 4 Physiopathology of symptoms in heart failure. Adapted from Clark with permission from BMJ Group Ltd. ${ }^{135}$ Abbreviation: HF, heart failure. poorly related. For instance, patients with a very low LVEF may be asymptomatic, whereas subjects with just a slightly depressed LVEF may have severe disability. ${ }^{35}$ The apparent discordance is not well understood but may be explained in part by many noncardiac factors that contribute considerably to exercise tolerance such as changes in peripheral vascular function, skeletal muscle physiology, pulmonary dynamics, or neurohormonal and reflex autonomic activity. ${ }^{36,37}$ The existence of such noncardiac factors may explain why the hemodynamic improvement produced by several drugs may not be instantly or necessarily translated into improvement in clinical status.

An approach used to quantify the degree of functional limitation imposed by HF was first developed by the New York Heart Association (NYHA). Severity ranges from essentially asymptomatic status - well-treated patients in whom symptoms have been relieved (NYHA I) - or slight limitation in physical activity (NYHA II), to symptoms while walking on the flat (NYHA III) or even breathless at rest and essentially housebound (NYHA IV). To get an objective evaluation of exercise performance, some form of exercise testing is necessary. Corridor walk tests, particularly the sixminute walk test, are commonly used due to their low cost and simplicity. ${ }^{38}$ However, to explore exercise limitation in greater detail, testing with metabolic gas exchange measurement is more useful. Although the functional class tends to deteriorate over time, most patients do not typically show an inexorable worsening of symptoms. Instead, their severity characteristically fluctuates. Medical therapy and diet can have either favorable or adverse effects on functional capacity even in the absence of significant changes in ventricular function. Some patients may show notable recovery associated with improvement in structural and functional abnormalities. When such improvement is associated with drug therapy, that therapy should be continued indefinitely.

\section{Hospitalizations}

As HF progresses, decompensations are more frequent and, therefore, hospitalizations increasingly required. Admissions with HF may be triggered by a concomitant cardiovascular event such as a symptomatic tachyarrhythmia or unstable coronary syndrome, medical or dietary noncompliance, or a noncardiac condition such as infections or a newly diagnosed anemia (Table 5). Unfortunately, the precipitating event is not always apparent. HF hospitalizations account for a substantial portion of the overall costs of caring and may be associated with an astounding worsening in prognosis, particularly in the elderly population. In fact, $50 \%$ of patients are readmitted at six months and $25 \%$ to $35 \%$ are dead at 
Table 5 Common factors that precipitate hospitalization for heart failure

- Noncompliance with medical regimen, sodium and/or fluid restriction

- Acute myocardial ischemia

- Uncorrected high blood pressure

- Atrial fibrillation and other arrhythmias

- Recent addition of negative inotropic drugs (eg, verapamil, diltiazem, beta blockers)

- Pulmonary embolus

- Nonsteroidal anti-inflammatory drugs

- Excessive alcohol or illicit drug use

- Endocrine abnormalities (eg, diabetes mellitus, hyperthyroidism, hypothyroidism)

- Concurrent infections (eg, pneumonia, viral illnesses)

twelve months. ${ }^{39-43}$ Indeed, many HF trials now incorporate the need for hospital admission as an important endpoint to evaluate new therapies.

A decline in hospitalization rates has been observed in Western countries during the past decade. ${ }^{44}$ This may come as a surprise in the face of the predicted increase in age-adjusted prevalence of HF. However, admissions for HF do not reflect the occurrence and prognosis of the disease in the community, as they relate only to the more severe stages that need in-hospital evaluation and treatment. A fall in hospitalization rates may well be due to improved treatment and management of patients (eg, development of new drugs and devices, HF clinics). In addition, a growing number of patients in the terminal stages are being cared for in a home-based setting by their general practitioner, rather than admitted to a hospital.

\section{Mortality}

The most comprehensive figures on the prognosis of the 'average' HF patients have been obtained in populationbased research, in which incident cases were followed up carefully. ${ }^{45-49}$ Mortality rate is relatively high in the first few weeks after the occurrence of HF. However, following that period, the survival curve shows a much more gradual slope. According to data from different studies conducted in America and Europe, 30-day, 1-year, and 5-year mortality are around $10 \%$ to $20 \%, 30 \%$, and $65 \%$ respectively. The mortality rates are higher when only patients hospitalized for $\mathrm{HF}$ are taken into account. ${ }^{50}$ In contrast, the risk of death in the placebo-treated arm of large randomized trials tends to be lower. ${ }^{51}$ To understand such discrepancies, we have to bear in mind that the severity of disease in these patients is different from the average patient. HF subjects admitted to hospital are often at advanced stages, whereas participants in medical trials tend to be healthier.
The vast majority of HF deaths are related to cardiovascular causes. Estimates vary from 50\% to 90\%, again, depending on the population analyzed. Patients with relatively mild HF (NYHA functional class I and II) are more susceptible to arrhythmias and SCD while those in NYHA functional class III and IV often die from end-stage ventricular dysfunction. $^{5}$

Continuous advances in therapy are changing the prognosis in HF, and improving survival. For example, in the Framingham heart study, the 1- and 5-year mortality rates from $\mathrm{HF}$ in men declined from $30 \%$ and $70 \%$, respectively, in the period 1950 to 1969 to $28 \%$ and $59 \%$ in the period 1990 to 1999 . In women, 1-year mortality rates decreased from $28 \%$ to $24 \%$ and the 5 -year mortality rates decreased from $57 \%$ to $45 \%$ during the same period. ${ }^{46}$ These results have been confirmed in other population-based studies. ${ }^{52}$

Prognostic determinants in HF can be arbitrarily categorized in: patient characteristics and comorbidity, laboratory measurements, functional parameters and ventricular function, and interventions received (Table 6). ${ }^{53,54}$ Importantly, these prognostic determinants need not be causally related to the prognostic outcome. Age, for example, is an important prognostic marker in many diseases even after adjustment for other factors. Although age per se may not be causally implicated, it is associated with other, often immeasurable, conditions that are etiologically involved. Apart from age, the NYHA classification has long been recognized as an important indicator of survival. The prognosis of HF obviously relates to the cause of HF; patients with HF caused by alcohol abuse may recover completely, while the 1-year mortality in an acute MI complicated by HF exceeds $50 \%$. Comorbidities known to influence survival unfavorably include renal dysfunction, depression, and anemia. For the reasons outlined above, this does not imply that correction, if possible, of these factors improved survival (eg, treatment with darbepoetin alpha failed to reduce outcomes in $\mathrm{HF}$ patients with anemia ${ }^{55}$ ).

By using a combination of variables, prognostic scores have been developed. One of the most popular is the Seattle HF model (validated extensively in five cohorts with a total of $9942 \mathrm{HF}$ patients). ${ }^{53}$ A web-based calculator is available at www.seattleheartfailuremodel.org.

\section{Economic costs}

The economic burden of HF is significant. Approximately $1 \%$ to $2 \%$ of total health care expenditure is attributed to the diagnosis, treatment, and prevention of $\mathrm{HF}^{56,57}$ A large share of this expenditure is related to the costs of long-term 
Table 6 Main prognostic factors in heart failure

\begin{tabular}{llll}
\hline $\begin{array}{l}\text { Patient characteristics } \\
\text { and comorbidity }\end{array}$ & $\begin{array}{l}\text { Functional parameters and } \\
\text { ventricular function indices }\end{array}$ & $\begin{array}{l}\text { Laboratory } \\
\text { measurements }\end{array}$ & $\begin{array}{l}\text { Interventions } \\
\text { received }\end{array}$ \\
\hline Age & NYHA class & CT ratio & ACEIs/ARBs \\
Gender & 6 min walk test & BNP/NTproBNP & BBs \\
Aetiology & LVEF & Hemoglobin & Aldosterone antagonists \\
Diabetes & Ventricular mass & Creatinine & HDZ-nitrates \\
Renal dysfunction & & QRS duration & ICD \\
Anemia & & Sodium levels & CRT \\
Depression & & & LVAD \\
& & & Heart transplantation \\
\hline
\end{tabular}

Adapted from Mosterd and Hoes with permission from BMJ Group Ltd. ${ }^{5}$

Abbreviations: ACEls, angiotensin converting enzyme inhibitors; ARBs, angiotensin receptor blockers; BNP, brain natriuretic peptide; CRT, cardiac resynchronization therapy; CT ratio, cardiothoracic index; HDZ, hydralazide; ICD, implantable cardioverterdefibrillator; LVAD, left ventricle assist device; LVEF, left ventricular ejection fraction; NT, N-terminal; NYHA, New York Heart Association.

complications and productivity losses. In order to manage these costs, health care providers increasingly have to focus on economically attractive interventions. Pharmacoeconomic analyses aid the systematic selection of cost-effective drug therapy in an era of increasing cost-containment.

\section{Treatment}

The American College of Cardiology (ACC)/American Heart Association (AHA) guidelines have identified four stages of HF. ${ }^{1}$ The first two stages are evidently not appropriately termed as HF. Stage A consists of patients with conditions that are associated with an increased risk for developing HF. Subjects with asymptomatic structural and/or functional LV disease constitute stage B. Symptomatic and terminal $\mathrm{HF}$ patients are included in stages $\mathrm{C}$ and $\mathrm{D}$, respectively. Importantly, this classification provides a stepwise approach to HF care; in every stage, several interventions are indicated in order to improve clinical status and/or prognosis (Figure 4). Each of these will be discussed in detail below.

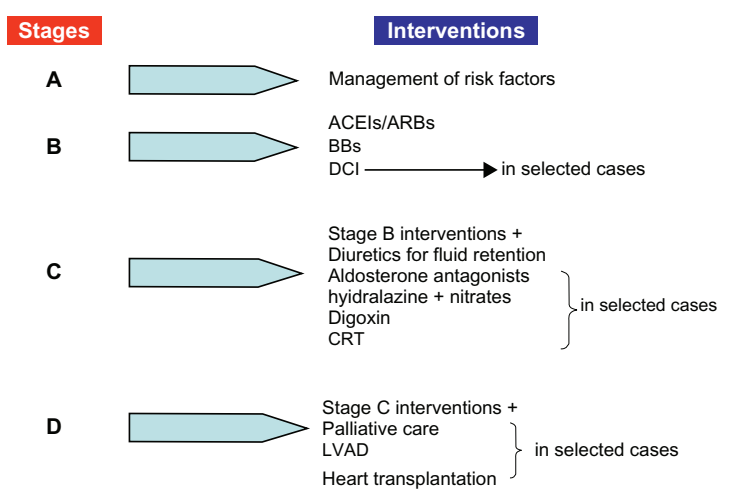

Figure 5 American College of Cardiology (ACC)/American Heart Association (AHA) stages and therapeutic management of HF.

Abbreviations: BBs, beta-blockers; ACEls, angiotensin converting enzyme inhibitors; $A R B s$, angiotensin receptor blockers; CRT, cardiac resynchronization therapy; DCI, Diseases and Conditions Index; ICD, implantable cardioverterdefibrillator; LVAD, left ventricular assist device.
The goals of treatment are reduction in symptoms, a decrease in the rate of hospitalization, and the prevention of premature death. The cornerstone of treatment is pharmacologic therapy. Lifestyle modification may also be needed. Surgery, implantable devices, or even heart transplantation may be required in selected cases.

\section{Organization of care}

Multidisciplinary intervention focused on educating patients, their families, and caregivers about HF, its treatment, in order to warrant adherence and optimize its effects, ${ }^{58}$ and the early recognition of and response to clinical worsening (eg, decrease in functional capacity or weight gain), with a guidance on flexible dosing of diuretics, has been shown to reduce the rate of hospital admissions and mortality. ${ }^{59}$ The Leonardo project, a care management initiative involving nurses, general practitioners, specialists, and patients conducted in a primary health care system, demonstrated pronounced effectiveness in increasing subjects' knowledge about their disease, self-care, and ability to make changes in health behaviors. ${ }^{60}$

Remote device monitoring (eg, electrocardiogram, blood pressure, body weight) coupled with medical telephone support (telemonitoring) may help to detect early signs of cardiac decompensation, allowing optimization of therapy. A recent Cochrane review concluded that telemonitoring reduced the rate of death from any cause by $44 \%$ and the rate of HF-related hospitalizations by $21 \% .{ }^{61}$ However, the quality of the methods used in the included studies was variable and many were small. The Tele-HF (Telemonitoring to Improve Heart Failure Outcomes) trial, a large study that randomized 1653 patients who had recently been hospitalized for HF to undergo either telemonitoring or usual care, found no benefits of this strategy. ${ }^{62}$ The ongoing TIMI-HF (Telemedical Interventional Monitoring In Heart Failure) trial will provide more data on the effects of this intervention. ${ }^{63}$ 
Tests such as standard blood analysis or echocardiograms should be scheduled only when needed (eg, to check ion levels and renal function in patients on diuretics, to reassess $\mathrm{EF}$ in cases of clinical deterioration or improvement). Despite the efficacy of brain natriuretic peptide (BNP) and N-terminal pro-B-type natriuretic peptide (NT-proBNP) measurements for the diagnosis of $\mathrm{HF}^{6}{ }^{64}$ their serial determinations to guide treatment is controversial. ${ }^{65}$

End-of-life palliative care should be available for individuals with end-stage HF. ${ }^{66}$

\section{Lifestyle and exercise}

Restriction of sodium intake is routinely recommended although it is based on little evidence. ${ }^{1,2}$ Several studies have demonstrated that exercise training improves quality of life as well as functional capacity, systolicdiastolic function and BNP and NT-proBNP expression. ${ }^{67}$ Nevertheless, it remains questionable whether this intervention reduces cardiac deaths and hospitalizations and whether disease severity predicts which patients are most likely to benefit. ${ }^{68,69}$

\section{Pharmacological therapy}

Although several therapeutic agents have proved to reduce morbidity and mortality in patients with HFDEF, no treatment has yet been shown to substantially improve clinical outcomes in patients with HFPEF. Therefore, we will focus our review on pharmacological therapy for HF patients with depressed systolic function.

The pathophysiological aspects of HF are essential for understanding drug actions and clinical trial designs. The development of HF is characterized by an initial cardiac injury that triggers a cascade of neurohormonal responses. Either an acute (MI) or a chronic (HBP) insult may alter the loading conditions of a normal ventricle, inducing stretching of myocardial fibers or their loss. This condition evokes activation of the RAAS and the sympathetic nervous system. In the short term, these actions are beneficial and adaptive, maintaining organ perfusion. However, in the long run, this abnormal neurohormonal setting leads to myocyte hypertrophy, apoptosis, and fibrotic proliferation, resulting in adverse remodeling and pump dysfunction. The consequences of these structural changes are a reduction in stroke volume, an increase in systemic vascular resistance, and the development of the signs and symptoms of congestion and hypoperfusion. Neurohormonal stimulation, therefore, will be the main target of most pharmacological agents for HF. Others, such as diuretic or digoxin, will not actuate in the feedback

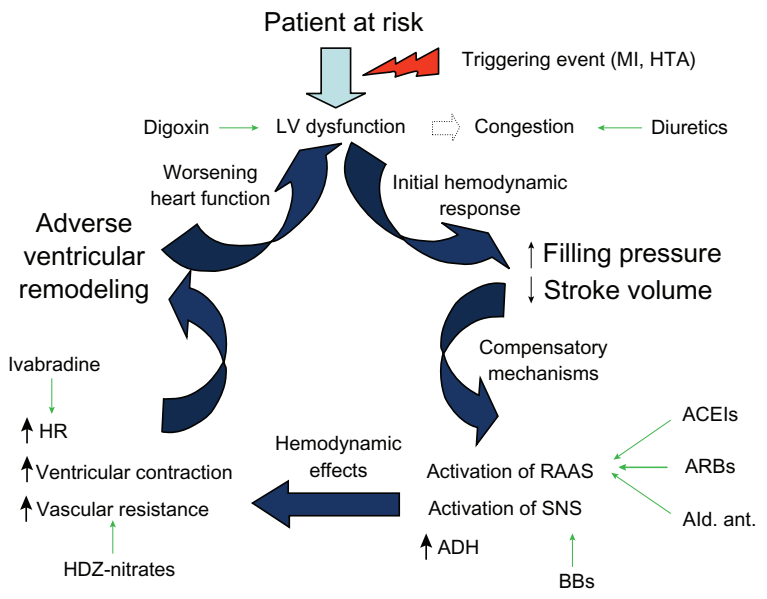

Figure 6 Physiopathology of heart failure and sites of action of the main pharmacological agents.

Adapted from Ramani et al. ${ }^{70}$

Abbreviations: $A C E l s$, angiotensin converting enzyme inhibitors; $A D H$, antidiuretic hormone; ald. ant., aldosterone antagonist; ARBs, angiotensin receptor blockers; BBs, beta-blockers; HDZ, hydralazide; HR, heart rate; HTA, heart transplant alone; LV, left ventricle; MI, myocardial infarction; RAAS, renin-angiotensin-aldosterone system; SNS, sympathetic nervous system.

mechanisms of the disease but will be helpful in symptomatic release (Figure 6). ${ }^{70}$

\section{Diuretics}

Diuretics provide rapid relief for the signs and symptoms of congestion. Because no studies have yet demonstrated the long-term benefit of these drugs in terms of mortality, they should be prescribed only to patients who have evidence of, or a prior history of, fluid retention. Due to their potency, loop diuretics have emerged as the preferred agents for use in most subjects; however, thiazide diuretics may be preferred in hypertensive HF with mild congestion because they present a more persistent effect on BP. The timing of administration can be altered for social convenience. Managing diuretic dosage is very important. The lowest dose needed to achieve an edema-free state ('dry weight') should be used (Table 7). Inappropriately low doses will result in fluid retention, which can increase the risk of treatment with beta-blockers, whereas inappropriately high doses will lead to volume contraction, which can lead to hypotension and renal insufficiency. Patients with mild HF respond favorably to low doses because absorption of the drug from the bowel and delivery to the renal tubules is fast. However, at advanced stages, bowel edema and hypoperfusion may delay absorption and delivery, ${ }^{71}$ and therefore, increasing doses may be required to achieve an appropriate effect. In some cases even high doses of diuretic are ineffective. The intake of large amounts of dietary sodium, treatment with agents that can block their effects, 
Table 7 Diuretics, beta-blockers, angiotensin converting enzyme inhibitors, angiotensin receptor blockers, and aldosterone antagonists recommended in heart failure

\begin{tabular}{|c|c|c|}
\hline Loop diuretics $^{a}$ & Initial dose (mg) & Usual daily dose (mg) \\
\hline Furosemide & $20-40$ & $40-240$ \\
\hline Bumetanide & $0.5-1.0$ & $1-5$ \\
\hline Torasemide & $5-10$ & $10-20$ \\
\hline Thiazides $^{\mathrm{b}}$ & Initial dose (mg) & Usual daily dose (mg) \\
\hline Bendroflumethiazide & 2.5 & $2.5-10$ \\
\hline Hydrochlorothiazide & 25 & $12.5-100$ \\
\hline Metolazone & 2.5 & $2.5-10$ \\
\hline Indapamide $^{c}$ & 2.5 & $2.5-5$ \\
\hline ACEls & Initial dose (mg) & Target dose (mg) \\
\hline Captopril & $6.25 \mathrm{ttd}$ & $50-100 \mathrm{ttd}$ \\
\hline Enalapril & $2.5 \mathrm{td}$ & $10-20$ td \\
\hline lisinopril & $2.5-5.0$ od & $20-35$ od \\
\hline Ramipril & 2.5 od & $5 \mathrm{td}$ \\
\hline Trandolapril & 0.5 od & 4 od \\
\hline ARBs & Initial dose (mg) & Target dose (mg) \\
\hline Candesartan & 4 to 8 od & 32 od \\
\hline Valsartan & 20 to 40 td & 160 td \\
\hline Losartan & 25 to 50 od & 50 to 100 od \\
\hline BBs & Initial dose (mg) & Target dose (mg) \\
\hline Carvedilol & $3.125 \mathrm{td}$ & $25 \mathrm{td}$ \\
\hline Bisoprolol & 1.25 od & 10 od \\
\hline Metoprolol & 12.5 od & 200 od \\
\hline Nevibolol & 1.25 od & 10 od \\
\hline Ald. ant. & Initial dose (mg) & Target dose (mg) \\
\hline Spironolactone & 25 od & $25-50$ od \\
\hline Eplerenone & 25 od & 50 od \\
\hline
\end{tabular}

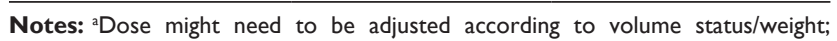

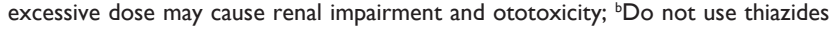
if eGFR. $30 \mathrm{~mL} / \mathrm{min}$, except when prescribed synergistically with loop duretics; Indapamide is non-thiazide sulfonamide.

Abbreviations: BBs, beta-blockers; ACEls, angiotensin-converting enzyme inhibitors; Ald. ant., aldosterone antagonists; ARBs, angiotensin receptor blockers; eGFR, estimated glomerular filtration rate; od, once daily; td, twice daily; ttd, three times daily.

such as nonsteroidal anti-inflammatories, ${ }^{72}$ or significant impairment of renal function or perfusion ${ }^{73}$ may be the cause of such a situation. Generally, diuretic resistance can be overcome by parenteral administration (continuous infusion may be more helpful than bolus injection), ${ }^{74}$ the use of two or more diuretics in combination (eg, furosemide and metolazone),${ }^{75}$ or the addition of drugs that increase renal blood flow (eg, positive inotropic agents). Diuretics can cause the depletion of important cations (potassium and magnesium), which may predispose patients to serious cardiac arrhythmias. Potassium deficits can be corrected by the short-term use of potassium supplements. Magnesium supplements may also be required. Concomitant administration of angiotensin-converting enzyme inhibitors (ACEIs) alone or in combination with potassium-retaining agents (such as spironolactone) can prevent electrolyte depletion in most patients, and thus, when these drugs are prescribed long-term, oral potassium supplementation frequently is not needed and may be deleterious.

\section{ACEls}

ACEIs are the most comprehensively studied agents in HF. These drugs not only interfere with the RAAS but also enhance the action of kinins and kinin-mediated prostaglandins, which may have beneficial effects in cardiac remodeling as seen in animal models. ${ }^{76-78}$ ACEIs have been evaluated in a large number of placebo-controlled trials involving patients with a reduced LVEF ( $<35 \%$ to $40 \%$ ) and a wide range of severity of HF (from asymptomatic LV impairment to NYHA functional class IV). These studies demonstrated that ACEIs improve symptoms, mortality, and the combined risk of death or hospitalization..$^{79}$ Although available data suggests that there are no differences among ACEIs in their effects, those used in clinical trials are recommended (Table 6). Treatment should be initiated at low doses followed by gradual increments attempting to reach target doses of clinical trials or the highest tolerated. ${ }^{1,2}$ The clinical response is generally delayed and may require several weeks, months, or longer to become apparent. ${ }^{80}$ However, even if symptoms do not improve, long-term treatment with an ACEI should be maintained to reduce the risk of death or hospitalization. The most common side effect of these agents is related to the suppression of angiotensin stimulation (hypotension and worsening of renal function) and to kinin enhancement (angioedema and cough).

- Symptomatic hypotension (eg, dizziness) often improves with time although the dose of diuretics and other hypotensive agents may need to be reduced.

- An increase in serum creatinine is expected after the initiation of an ACEI but is not considered clinically important unless rapid and substantial. Renal function is usually restored after a reduction in the dose of concomitantly administered diuretics, so these patients can generally be managed without withdrawing treatment with ACEIs. ${ }^{81}$

- Hyperkaliemia is generally seen in patients whose renal function deteriorates or who are taking oral potassium supplements or potassium-sparing diuretics.

- Cough is the most common reason for the withdrawal of long-term treatment with ACEIs. ${ }^{82}$ Its frequency is approximately $5 \%$ to $10 \%$ in white patients of European descent and rises to nearly $50 \%$ in Chinese patients. ${ }^{83}$

- Angioedema occurs in $<1 \%$ of patents taking an ACEI but is more frequent in black patients. Because its occurrence may be life-threatening, the clinical suspicion of this reaction justifies subsequent avoidance of all ACEIs for the lifetime of the patient. ${ }^{82}$ 


\section{Angiotensin receptor blockers}

Circulating levels of angiotensin II increase to pretreatment levels with long-term ACEI inhibition. ${ }^{84}$ Angiotensin receptor blockers (ARBs) bind competitively to the AT1 receptor, providing a downstream effect and thereby dampening this escape phenomenon. ${ }^{85}$ Besides, interference with the RAAS without inhibition of kininase would provide the benefits of ACEIs while minimizing their adverse reactions ${ }^{86}$ However, as mentioned before, it is now known that some of the benefits of ACEIs may be related to the accumulation of kinins, whereas some of the their side effects are related to the suppression of angiotensin II formation. A large metaanalysis of 24 randomized trials showed the superiority of ARBs to placebo in patients with intolerance to ACEIs and their noninferiority in all-cause mortality or hospitalizations when compared directly with ACEIs. ${ }^{87}$ Taking into account this evidence, ARBs are used as an alternative to ACEIs when cough or angioedema is developed. Because combination therapy of ACEIs and ARBs results in a modest decrease in hospitalization (relative risk reduction [RRR]: 17\%), an increase in side effects, and no benefits on mortality, ${ }^{88}$ its use is controversial. ${ }^{1,2}$ ARBs recommended in guidelines are listed in Table 7.

\section{Beta blockers}

The benefits of three beta-blockers (BBs), bisoprolol, metoprolol succinate ( $\beta_{1}$ receptor selective blockers), and carvedilol (which blocks $\alpha_{1}, \beta_{1}$, and $\beta_{2}$ receptors), have been assessed in several placebo-controlled trials enrolling patients with a reduced LVEF ( $<35 \%$ to $45 \%$ ), mostly under ACEIs therapy, from initial to advance stages of HF. ${ }^{89-93}$ Long-term treatment with BBs has been shown to lessen symptoms, reduce mortality and the combined risk of death and hospital admission. In the SENIORS (Study of the Effects of Nebivolol Intervention on Outcomes and Rehospitalization in Seniors with heart failure) trial, nebivolol, another $\beta_{1}$ receptor blocker, demonstrated efficacy in reducing the combined endpoint of death or cardiovascular hospitalization in elderly patients ( $>70$ years) with HF. ${ }^{94}$ Although no randomized controlled trials of BBs in individuals with asymptomatic LV dysfunction have been completed, their use (especially in those with CAD) is encouraged. ${ }^{2}$ Bearing in mind that most participants in $\mathrm{BB}$ trials were not on target doses on ACEIs and the fact that adding a BB produces a greater improvement in clinical status and mortality than increasing ACEIs, ${ }^{95,96}$ patients do not need to be on high doses of ACEIs before initiating therapy with BBs. Dose titration and time to clinical response considerations for ACEIs also apply to BBs (Table 7). Because long-term treatment with $\mathrm{BBs}$ reduces the risk of worsening HF, discontinuation of these drugs after an episode of decompensation is not recommended. ${ }^{1,2}$ However, in unstable subjects it may be prudent to reduce its dose temporarily until the basal status is recovered.

The most common side effects of BBs include:

- Fatigue or weakness. In many cases it resolves spontaneously within several weeks; however, in some cases, it may be severe enough to limit dose increase or even necessitate treatment withdrawal.

- Bradycardia. The slowing of heart rate (HR) is generally well tolerated. Nevertheless, when symptoms or an advanced heart block is developed BB dose should be reduced.

- Symptomatic hypotension may be managed by administering BBs and ACEIs at different times during the day. If this is ineffective, a temporary reduction in the dose of diuretics (in patients who are volume depleted) or ACEIs may be effective.

\section{Aldosterone antagonists}

Although short-term therapy with both ACEIs and ARBs can lower circulating levels of aldosterone, such suppression may not be sustained during long-term treatment. ${ }^{97}$ This observation may be important because aldosterone promotes sodium retention, electrolyte imbalances, and endothelial dysfunction and may directly contribute to myocardial fibrosis. ${ }^{98}$ In the RALES (Randomized Spironolactone Evaluation Study) trial, a low dose of spironolactone, the most widely used aldosterone antagonist, added to ACE therapy in NYHA class III and IV patients, reduced mortality and HF hospitalizations. Functional class also improved. ${ }^{99}$ The EPHESUS (Eplerenone Post-Acute Myocardial Infarction Heart Failure Efficacy and Survival Study) trial investigated the newer aldosterone antagonist eplerenone in subjects with LVEF $\leq 40 \%$ and clinical evidence of HF or diabetes mellitus within 14 days after MI, and found a decrease in the risk of death. ${ }^{100}$ The recently published EMPHASIS-trial, whose participants had an LVEF $\leq 35 \%$ and were in NYHA functional class II, showed that eplerenone significantly reduced mortality and hospital admissions. ${ }^{101}$ This promising result may extend the actual indication for aldosterone antagonists (NYHA functional class III-IV) in HF to early stages of the disease. The main side effects related to aldosterone antagonists are hyperkalemia and gynecomastia. 
- Hyperkalemia is a concern, especially in subjects with underlying chronic kidney disease, so serum potassium levels must be closely monitored.

- Gynecomastia can occur during therapy with spironolactone but not in patients treated with eplerenone, and thus, switching from one agent to the other one may solve the problem.

The dosage of aldosterone antagonists is listed in Table 7.

\section{Hydralazine and nitrates}

Hydralazine produces arterial vasodilation and systemic vascular resistance reduction via modulation of intracellular calcium kinetics, and nitrates are transformed in smooth muscle cells into nitric oxide, which stimulates cyclic guanosine monophosphate production and subsequent arterial vasodilation. This combination increases survival in HF, but not as much as with ACEIs or ARBs. ${ }^{102,103}$ The A-Heft trial, conducted in African Americans with advanced HF who were receiving standard therapy (including BBs and ACEIs), found that the addition of a fixed-dose isosorbidedinitrate and hydralazine enhanced survival and decreased hospitalizations. ${ }^{104}$ According to these data, combination therapy with hydralazine and nitrates may be an option for patients in which ACEIs or ARBs are contraindicated and also in African American HF subjects who remain symptomatic (NYHA functional class III-IV) despite optimal medical therapy. ${ }^{1,2}$

\section{Digoxine}

In addition to their mild inotropic effect, digitalis glycosides attenuate carotid sinus baroreceptors and have sympathoinhibitory effects that produce a decrease in norepinephrine, renin, and possibly aldosterone levels. ${ }^{105,106}$ In the only randomized-controlled trial of digoxin therapy (DIG trial) a reduction in hospitalizations (RRR 28\%) among individuals with HF and LVEF $<45 \%$ was found, although no overall mortality benefit was achieved. ${ }^{107}$ In daily practice, digoxin is used in addition to BBs to control HR in patients with atrial fibrillation as well as in those with persisting symptoms even with optimal medical treatment. ${ }^{1,2}$ Dosage should be adjusted to obtain serum levels between 0.6 and $1.2 \mathrm{ng} / \mathrm{mL}$. Common side effects include bradyarrhythmias and tachyarrhythmias (digoxin-specific Fab antibody fragments may be required in some cases), gastrointestinal symptoms (eg, anorexia, nausea, and vomiting), and neurological complaints (eg, visual disturbances, disorientation, and confusion). Although digitalis toxicity is commonly associated with high serum digoxin levels $(>2 \mathrm{ng} / \mathrm{mL})$ it may occur with lower levels, especially if hypokalemia coexists.

\section{Surgery}

\section{Coronary revascularization}

A meta-analysis of 24 studies investigating late survival in patients with ischemic HF treated with coronary artery bypass grafting (CABG) or medical therapy showed a RRR of $79 \%$ in annual mortality in those with myocardial viability. Nevertheless, no incremental benefit with CABG was found in individuals without substantial viability. ${ }^{108}$ Revascularization is strongly supported in patients with angina, whereas there is no evidence to sustain it in individuals with multivessel CAD but no ischemic symptoms. An ongoing randomized trial will clarify this matter. ${ }^{109}$

\section{Mitral valve repair}

Functional MR, characterized by annular dilatation and leaflet non-coaptation in the setting of anatomically normal papillary muscles, chordal structures, and valve leaflets, is frequent in patients with HF. Although severe functional MR is associated with poor prognosis, it has been demonstrated that valve repair improves only symptoms but does not reduce mortality. Besides, recurrence in the first year may reach up to $35 \%$ of cases. Therefore the indication for this surgical technique is controversial and must be individualized. ${ }^{110}$

Ischemic MR found in patients with previous MI is typically associated with leaflet tethering and displacement related to abnormal LV wall motion and geometry. Despite current guidelines recommending mitral valve repair in patients with moderate and severe ischemic MR who are considered for CABG surgery, long-term benefits are still unclear. ${ }^{111}$

\section{Ventricular reconstruction}

Multiple surgical techniques to reduce LV volume and thereby alleviate wall stress have been utilized. The recently published STICH (Surgical Treatment of Ischemic Heart Failure) trial randomized patients with ischemic LV dysfunction undergoing $C A B G$ to isolated $C A B G$ versus CABG plus surgical ventricular reconstruction. Although surgical reconstruction reduced LV volumes, no difference in mortality or hospital admissions was found. ${ }^{112}$ On the basis of these results, routine surgical LV reconstruction in addition to $\mathrm{CABG}$ is not recommended.

\section{Devices}

Implantable cardioverter-defibrillator

Implantable cardioverter-defibrillator (ICD) reduces the risk of SCD due to severe ventricular arrhythmias. Patients at higher risk are those with a previous MI and a severely 
reduced LVEF. The MADIT II (Multicentric Automatic Defibrillator Implantation II) trial, whose participants had a nonrecent $\mathrm{MI}$ and $\mathrm{LVEF}<30 \%$, found a significant survival benefit after ICD implantation. ${ }^{113}$ Similar results were showed SCD-HeFT (Sudden Cardiac Death in Heart Failure) trial which evaluated patients with nonischemic or ischemic LV systolic dysfunction (LVEF $<35 \%)$. ${ }^{114}$ According to current guidelines, ICD is indicated for secondary prevention in patients who survive an unprovoked episode of ventricular fibrillation or sustained ventricular tachycardia and for primary prevention in patients with LV dysfunction (LVEF $\leq$ $35 \%$ ). In ischemic LV dysfunction, evaluation of LVEF and subsequent device implantation should be done three months after an elective revascularization and 40 days after a prior MI. NYHA functional class II or III, optimal medical therapy, and expected survival with good functional status for $>1$ year are required to implant an ICD in nonischemic LV systolic dysfunction. In cases of ischemic LV dysfunction this indication is extended to NYHA functional class I. ${ }^{115}$

\section{Cardiac-resynchronization therapy (CRT)}

Intraventricular conduction delays, identified by a QRS interval of $>120 \mathrm{~ms}$, occur in up to one-third of patients with severe systolic HF, and are associated with dyssynchronous contraction of the LV, which leads to impaired emptying and, in some patients, MR. ${ }^{116}$ Early studies showed that CRT has a positive effect on reverse remodeling (manifested by a decrease in LV volumes and an increase in LVEF), improves exercise capacity, and reduces symptoms. ${ }^{117}$ The CARE-HF (Cardiac Resynchronization in Heart Failure) trial was the first study to demonstrate a benefit in all-cause mortality with this treatment. ${ }^{118}$ A meta-analysis of 14 randomized trials of CRT confirmed a significant lessening in morbidity and mortality. ${ }^{119}$ In contrast, this therapy has not been successful in HF patients with narrow QRS. ${ }^{120}$ Although many echocardiographic parameters of dyssynchronous have been proposed to identify candidates for CRT, no one has shown efficacy for predicting responders, ${ }^{121}$ and therefore, to date, they are not routinely used in daily practice. The recently published MADIT-CRT trial, which involved patients with NYHA functional class I or II, LVEF of $30 \%$ or less, and wide QRS intervals ( $\geq 130 \mathrm{~ms}$ ), found that CRT added to an ICD improved ventricular function and reduced the risk of worsening HF in comparison with ICD alone. These effects were most marked in subjects with a QRS interval of $\geq 150 \mathrm{~ms} .{ }^{122}$ Participants in the REVERSE (Resynchronization Reverses Remodeling in Systolic Left Ventricular Dysfunction) trial (NYHA function class I or II, $\mathrm{LVEF} \leq 40 \%$, QRS duration $\geq 120 \mathrm{~ms}$, and $\mathrm{LV}$ end-diastolic
Table 8 Actual European recommendations for cardiac resynchronization therapy

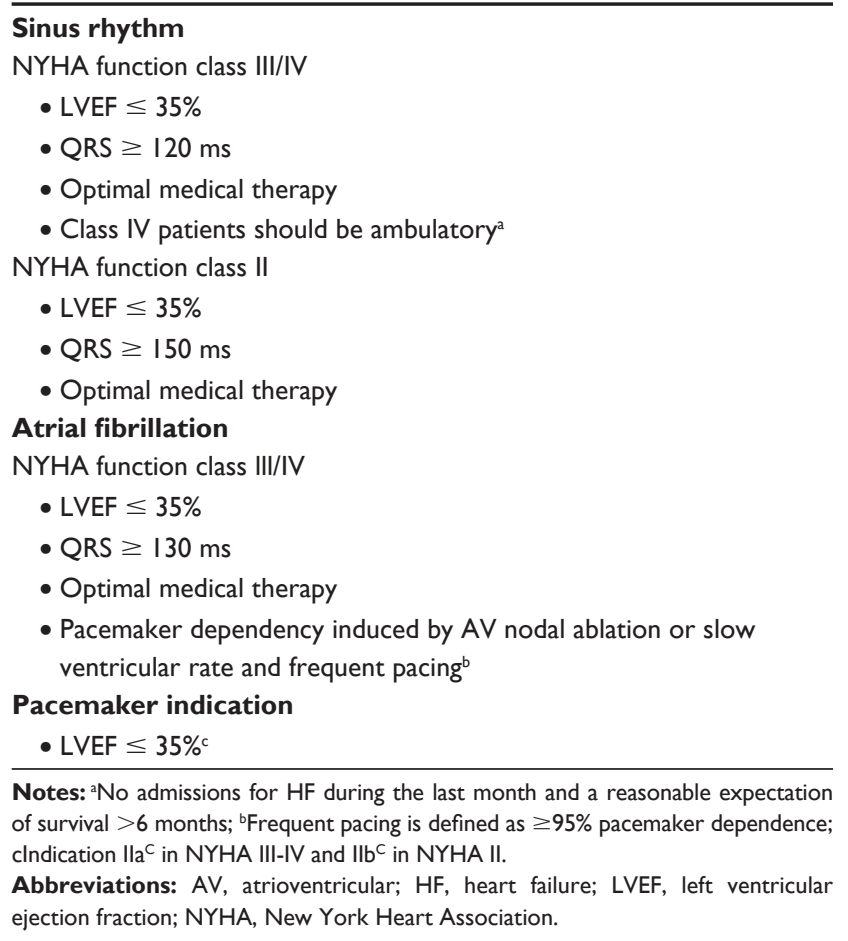

diameter $\geq 55 \mathrm{~mm}$ ) were randomly assigned to CRT activated versus CRT off. After 12 months, a positive effect on reverse remodeling was achieved in the CRT-activated group, but no difference in clinical outcomes was found. ${ }^{123}$ The European sample of REVERSE comprised 262 patients, followed up to 24 months. In this population, fewer patients assigned to CRT worsened clinically. ${ }^{124}$ Similarly, the time to first hospitalization for HF or to death from any cause was significantly delayed. The results from these two trials have recently changed the European Society of Cardiology recommendations for CRT (Table 8). ${ }^{125}$ The advantage of CRT plus ICD (CRT-D) over CRT alone in terms of survival has not been adequately addressed. However, because of the documented effectiveness of ICD therapy for prevention of SCD, the use of a CRT-D device is commonly preferred.

\section{Left ventricular assist devices}

Given the shortage of organ donors there has been a growing interest in left ventricular assist devices (LVAD) as a bridge to transplantation or even as a definitive therapy for end-stage HF individuals. The REMATCH trial, conducted in patients with terminal HF ineligible for heart transplantation, showed that LVAD increased 1-year survival rates as compared with medical treatment (52\% vs $25 \%$ respectively). ${ }^{126}$ Technological advances have led to the development of more effective and safer devices. In a recent study 
comparing new continuous flow LVAD with old pulsatile volume-displacement LVAD in subjects with end-stage HF, the 2-year survival was significantly higher with the new device than with the older (46\% vs $11 \%)$. ${ }^{127}$ Despite these promising results, current devices are expensive and may cause serious complications such as infection, bleeding, and malfunction. Therefore, candidates for this therapy must be carefully selected.

\section{Heart transplantation}

Heart transplantation is a last resort for patients with refractory HF. The development of immunosuppressive agents has dramatically reduced the rate of graft rejection and led to good survival rates (the estimated half-life heart transplantation exceeds 10 years) with a good quality of life. ${ }^{128}$ However, serious comorbidities must be ruled out and an ability to adhere to the intensive postoperative medical treatment and follow-up required should be confirmed before offering a patient this therapeutic option.

\section{Novel therapies}

Ivabradine acts on the $\mathrm{I}_{\mathrm{f}}$ ion current, which is highly expressed in the sinoatrial node. $\mathrm{I}_{\mathrm{f}}$ is a mixed $\mathrm{Na}^{+}-\mathrm{K}^{+}$inward current activated by hyperpolarization and modulated by the autonomic nervous system. It is one of the most important ionic currents for regulating pacemaker activity in the sinoatrial node. Ivabradine selectively inhibits this current in a dose-dependent manner, slowing the HR. The drug has few other, if any, known cardiac effects. The SHIFT (Systolic Heart Failure Treatment with the IF Inhibitor Ivabradine) trial investigated the effects of ivabradine in HF patients with reduced LVEF $(\leq 35 \%)$ and $\mathrm{HR}>70$ beats per minute, showing a reduction in the rate of cardiovascular death and cardiovascular hospital admissions. ${ }^{129}$ These results confirm the importance of HR in HF and support the concept that its decrease contributes significantly to reduce outcomes.

\section{Treatment of HFPEF}

Identification of specific therapeutic agents has been disappointing. Effective drugs in HFDEF such as ACEIs, ARBs, BBs, and digoxin showed no benefits in HFPED. ${ }^{130-133}$ Therefore, guidelines focus on appropriate treatment of the underlying cause (basically BP and ischemia), rate/rhythm control if AF is developed, and control of pulmonary congestion with diuretic agents. ${ }^{1,2}$ Venodilators such as nitrates should be used with caution because decreases in preload may lead to an excessive reduction in LV filling, resulting in hypotension and syncope.

\section{Treatment of isolated right HF}

The most important aspect of managing right HF is tailoring therapy to its specific cause. In contrast to patients with chronic left HF, patients with right HF often have significantly abnormal afterload (eg, pulmonary hypertension) or valvular heart disease (eg, acquired or congenital pulmonary or tricuspid disease). It is therefore not surprising that the selected treatment should primarily target the etiology of the disease. Sodium and fluid restriction and judicious use of diuretics all help to optimize preload which, in the majority of patients, is achieved at normal right atrial pressure ( $<6 \mathrm{mmHg}$ ). Only small studies suggest a beneficial role for beta blockade or ACE inhibitors. Primary prevention of sudden death using defibrillators is recommended mainly in patients with ARVC and tetralogy of Fallot. In the setting of acute right HF, every effort should be made to avoid systemic hypotension, as this could lead to myocardial ischemia and further hypotension. ${ }^{134}$

\section{Disclosure}

The authors declare no conflicts of interest.

\section{References}

1. Hunt SA, Abraham WT, Chin MS, et al. 2009 Focused update incorporated into the ACC/AHA 2005 Guidelines for the Diagnosis and Management of Heart Failure in Adults: a report of the American College of Cardiology Foundation/American Heart Association Task Force on Practice Guidelines: developed in collaboration with the International Society for Heart and Lung Transplantation. J Am CollCardiol. 2009;53(15):e1-e90.

2. Dickstein K, Cohen-Solal A, Filippatos G, et al. ESC Guidelines for the diagnosis and treatment of acute and chronic heart failure 2008: the Task Force for the Diagnosis and Treatment of Acute and Chronic Heart Failure 2008 of the European Society of Cardiology. Developed in collaboration with the Heart Failure Association of the ESC (HFA) and endorsed by the European Society of Intensive Care Medicine (ESICM). Eur Heart J. 2008;29(19):2388-2442.

3. Bhatia RS, Tu JV, Lee DS, et al. Outcome of heart failure with preserved ejection fraction in a population-based study. $N$ Engl J Med. 2006; 355(3):260-269.

4. Owan TE, Hodge DO, Herges RM, Jacobsen SJ, Roger VL, Redfield MM. Trends in prevalence and outcome of heart failure with preserved ejection fraction. $N$ Engl J Med. 2006;355(3): 251-259.

5. Mosterd A, Hoes AW. Clinical epidemiology of heart failure. Heart. 2007;93(9):1137-1146.

6. Fox KF, Cowie MR, Wood DA, et al. Coronary artery disease as the cause of incident heart failure in the population. Eur Heart J. 2001; 22(3):228-236.

7. Gheorghiade M, Bonow RO. Chronic heart failure in the United States: a manifestation of coronary artery disease. Circulation. 1998; 97(3):282-289.

8. Repetto A, Dal Bello B, Pasotti M, et al. Coronary atherosclerosis in end stage idiopathic dilated cardiomyopathy: an innocent bystander? Eur Heart J. 2005;26(15):1519-1527.

9. Hedrich O, Jacob M, Hauptman PJ. Progression of coronary artery disease in non-ischemic dilated cardiomyopathy. Coron Artery Dis. 2004;15(5):291-297. 
10. Shizukuda Y, Sonnenblick EH, Le Jemtel TH, Forman R. Coronary flow reserve of nonischemic heart failure. Congest Heart Fail. 1999; 5(5):208-215.

11. Santagata P, Rigo F, Gherardi S, et al. Clinical and functional determinants of coronary flow reserve in non-ischemic dilated cardiomyopathy: an echocardiographic study. Int J Cardiol. 2005;105(1):46-52.

12. Sutton MG, Sharpe N. Left ventricular remodeling after myocardial infarction: pathophysiology and therapy. Circulation. 2000; 101(25):2981-2988.

13. Fenelon G, Wijns W, Andries E, Brugada P. Tachycardiomyopathy: mechanisms and clinical implications. Pacing Clin Electrophysiol. 1996;19(1):95-106.

14. Wijns W, Vatner SF, Camici PG. Hibernating myocardium. $N$ Engl J Med. 1998;339(3):173-181.

15. He J, Ogden LG, Bazzano LA, Vupputuri S, Loria C, Whelton PK. Risk factors for congestive heart failure in US men and women: NHANES I epidemiologic follow-up study. Arch Intern Med. 2001; 161(7):996-1002.

16. Vasan RS, Levy D. The role of hypertension in the pathogenesis of heart failure: a clinical mechanistic overview. Arch Intern Med. 1996; 156(16):1789-1796.

17. Levy D, Larson MG, Vasan RS, Kannel WB, Ho KK. The progression from hypertension to congestive heart failure. JAMA. 1996; 275(20):1557-1562.

18. Lip GY, Felmeden DC, Li-Saw-Hee FL, Beevers DG. Hypertensive heart disease. A complex syndrome or a hypertensive 'cardiomyopathy'? Eur Heart J. 2000;21(20):1653-1665.

19. Weber KT, Sun Y, Guarda E. Structural remodelling in hypertensive heart disease and the roles of hormones. Hypertension. 1994; 23(6 Pt 2):869-877.

20. Inouye I, Massie B, Loge, et al. Abnormal left ventricular filling: an early finding in mild to moderate systemic hypertension. Am J Cardiol. 1984;53(1):120-126.

21. Smith VE, Schulman P, Karimeddini MK, White WB, Meeran MK, Katz AM. Rapid ventricular filling in left ventricular hypertrophy: II. Pathologic hypertrophy. J Am CollCardiol. 1985;5(4):869-874.

22. Pearson AC, Gudipati C, Nagelhout D, Sear J, Cohen JD, Labovitz AJ Echocardiographic evaluation of cardiac structure and function in elderly subjects with isolated systolic hypertension. J Am CollCardiol. 1991;17(2):422-430.

23. Devereux RB. Left ventricular diastolic dysfunction: early diastolic relaxation and late diastolic compliance. J Am CollCardiol. 1989; 13(2):337-339.

24. Marcus ML, Harrison DG, Chilian WM, et al. Alterations in the coronary circulation in hypertrophied ventricles. Circulation. 1987; 75(1 Pt 2):I19-I25.

25. González A, Fortuño MA, Querejeta R, et al. Cardiomyocyte apoptosis in hypertensive cardiomyopathy. Cardiovasc Res. 2003; 59(3):549-562.

26. Elliott P, Andersson B, Arbustini E, et al. Classification of the cardiomyopathies: a position statement from the European Society of Cardiology Working Group on Myocardial and Pericardial Diseases. Eur Heart J. 2008;29(2):270-276.

27. Burkett EL, Hershberger RE. Clinical and genetic issues in familial dilated cardiomyopathy. J Am CollCardiol. 2005;45(7):969-981.

28. Mestroni L, Maisch B, McKenna, et al. Guidelines for the study of familial dilated cardiomyopathies. Collaborative Research Group of the European Human and Capital Mobility Project on Familial Dilated Cardiomyopathy. Eur Heart J. 1999;20(2):93-102.

29. Elliott P, McKenna WJ. Hypertrophic cardiomyopathy. Lancet. 2004; 363(9424):1881-1891.

30. Harris KM, Spirito P, Maron MS, et al. Prevalence, clinical profile, and significance of left ventricular remodeling in the end-stage phase of hypertrophic cardiomyopathy. Circulation. 2006;114(3):216-225.

31. Fagard R. Athlete's heart. Heart. 2003;89(12):1455-1461.

32. Basso C, Corrado D, Marcus FI, Nava A, Thiene G. Arrhythmogenic right ventricular cardiomyopathy. Lancet. 2009;373(9671):1289-1300.
33. Engberding R, Yelbuz TM, Breithardt G. Isolated noncompaction of the left ventricular myocardium - a review of the literature two decades after the initial case description. Clin Res Cardiol. 2007;96(7):481-488.

34. Murphy RT, Thaman R, Blanes JG, et al. Natural history and familial characteristics of isolated left ventricular non-compaction. Eur Heart J. 2005;26(2):187-192. Erratum in: Eur Heart J. 2008;29(15):1925.

35. Franciosa JA, Park M, Levine TB. Lack of correlation between exercise capacity and indexes of resting left ventricular performance in heart failure. Am J Cardiol. 1981;47(1):33-39.

36. Coats AJ, Adamopoulos S, Radaelli A, et al. Controlled trial of physical training in chronic heart failure. Exercise performance, hemodynamics, ventilation, and autonomic function. Circulation. 1992;85(6):2119-2131.

37. Hambrecht R, Niebauer J, Fiehn E, et al. Physical training in patients with stable chronic heart failure: effects on cardiorespiratory fitness and ultrastructural abnormalities of leg muscles. J Am CollCardiol. 1995;25(6):1239-1249.

38. Rostagno C, Gensini GF. Six minute walk test: a simple and useful test to evaluate functional capacity in patients with heart failure. Intern Emerg Med. 2008;3(3):205-212.

39. Solomon SD, Dobson J, Pocock S, et al. Influence of nonfatal hospitalization for heart failure on subsequent mortality in patients with chronic heart failure. Circulation. 2007;116(13):1482-1487.

40. Fonarow GC, Heywood JT, Heidenreich PA, Lopatin M, Yancy CW; ADHERE Scientific Advisory Committee and Investigators. Temporal trends in clinical characteristics, treatments, and outcomes for heart failure hospitalizations, 2002 to 2004: findings from Acute Decompensated Heart Failure National Registry (ADHERE). Am Heart J. 2007; 153(6):1021-1028.

41. Brown DW, Haldeman GA, Croft JB, Giles WH, Mensah GA. Racial or ethnic differences in hospitalization for heart failure among elderly adults: Medicare, 1990 to 2000. Am Heart J. 2005;150(3):448-454.

42. Klapholz M, Maurer M, Lowe AM, et al. Hospitalization for heart failure in the presence of a normal left ventricular ejection fraction: results of the New York Heart Failure Registry. J Am CollCardiol. 2004;43(8):1432-1438.

43. Haldeman GA, Croft JB, Giles WH, Rashidee A. Hospitalization of patients with heart failure: National Hospital Discharge Survey, 1985 to 1995. Am Heart J. 1999;137(2):352-360.

44. Mosterd A, Reitsma JB, Grobbee DE. ACE inhibition and hospitalisation rates for heart failure in the Netherlands 1980-1999. The end of an epidemic? Heart. 2002;87(1):388-392.

45. Bleumink GS, Knetsch AM, Sturkenboom MC, et al. Quantifying the heart failure epidemic: prevalence, incidence rate, lifetime risk and prognosis of heart failure The Rotterdam Study. Eur Heart J. 2004; 25(18):1614-1619.

46. Levy D, Kenchaiah S, Larson MG, et al. Long-term trends in the incidence of and survival with heart failure. $N$ Engl J Med. 2002; 347(18):1397-1402.

47. Cowie MR, Wood DA, Coats AJ, et al. Survival of patients with a new diagnosis of heart failure: a population based study. Heart. 2000; 83(5):505-510.

48. Senni M, Tribouilloy CM, Rodeheffer RJ, et al. Congestive heart failure in the community: a study of all incident cases in Olmsted County, Minnesota, in 1991. Circulation. 1998;98(21):2282-2289.

49. Muntwyler J, Abetel G, Gruner C, Follath F. One-year mortality among unselected outpatients with heart failure. Eur Heart J. 2002; 23(23):1861-1866.

50. Blackledge HM, Tomlinson J, Squire IB. Prognosis for patients newly admitted to hospital with heart failure: survival trends in 12220 index admissions in Leicestershire 1993-2001. Heart. 2003; 89(6):615-620.

51. Brophy JM, Joseph L, Rouleau JL. Beta-blockers in congestive heart failure. A Bayesian meta-analysis. Ann Intern Med. 2001; 134(7): $550-560$.

52. Roger VL, Weston SA, Redfield MM, et al. Trends in heart failure incidence and survival in a community-based population. JAMA. 2004; 292(3):344-350. 
53. Levy WC, Mozaffarian D, Linker DT, et al. The Seattle Heart Failure Model: prediction of survival in heart failure. Circulation. 2006; 113(11):1424-1433.

54. Deedwania PC. The key to unraveling the mystery of mortality in heart failure: an integrated approach. Circulation. 2003;107(13): $1719-1721$

55. Ghali JK, Anand IS, Abraham WT, et al. Randomized double-blind trial of darbepoetinalfa in patients with symptomatic heart failure and anemia. Circulation. 2008;117(4):526-535.

56. Szucs TD, Sokolovic E. Economic significance of heart failure. An overview of costs and economics of therapy. Herz. 2000;25(5):538-546.

57. Stewart S, Jenkins A, Buchan S, McGuire A, Capewell S, McMurray JJ. The current cost of heart failure to the National Health Service in the UK. Eur J Heart Fail. 2002;4(3):361-371.

58. Mohammadi M, Ekman I, Schaufelberger M. Relationship between blood pressure levels and adherence to medication in patients with chronic heart failure: how come? Vasc Health Risk Manag. 2009;5(1):13-19.

59. Sochalski J, Jaarsma T, Krumholz HM, et al. What works in chronic care management: the case of heart failure. Health Aff (Millwood). 2009;28(1):179-189.

60. Ciccone MM, Aquilino A, Cortese F, et al. Feasibility and effectiveness of a disease and care management model in the primary health care system for patients with heart failure and diabetes (Project Leonardo). Vasc Health Risk Manag. 2010;6:297-305.

61. Inglis SC, Clark RA, McAlister FA, et al. Structured telephone support or telemonitoring programmes for patients with chronic heart failure. Cochrane Database Syst Rev. 2010;8:CD007228.

62. Chaudhry SI, Mattera JA, Curtis JP, et al. Telemonitoring in patients with heart failure. N Engl J Med. 2010;363(24):2301-2309.

63. Koehler F, Winkler S, Schieber M, et al. Telemedical Interventional Monitoring in Heart Failure (TIM-HF), a randomized, controlled intervention trial investigating the impact of telemedicine on mortality in ambulatory patients with heart failure: study design. Eur J Heart Fail. 2010;12(12):1354-1362.

64. Palazzuoli A, Gallotta M, Quatrini I, Nuti R. Natriuretic peptides (BNP and NT-proBNP): measurement and relevance in heart failure. Vasc Health Risk Manag. 2010;6:411-418.

65. Baibars M, Ibrahim A, Fang JC, Sipahi I. Natriuretic peptide-guided management of patients with heart failure: a decade of progress but still a controversy. Future Cardiol. 2010;6(6):743-747.

66. Jaarsma T, Beattie JM, Ryder M, et al. Palliative care in heart failure: a position statement from the palliative care workshop of the Heart Failure Association of the European Society of Cardiology. Eur J Heart Fail. 2009;11(5):433-443.

67. Smart N. Exercise training for heart failure patients with and without systolic dysfunction: an evidence-based analysis of how patients benefit. Cardiol Res Pract. 2010;2011.pii:837238.

68. Piepoli MF, Davos C, Francis DP, Coats AJ; ExTraMATCH Collaborative. Exercise training meta-analysis of trials in patients with chronic heart failure (ExTraMATCH). Br Med J. 2004;328(7433):189.

69. O'Connor CM, Whellan DJ, Lee KL, et al. Efficacy and safety of exercise training in patients with chronic heart failure: HF-ACTION randomized controlled trial. JAMA. 2009;301(14):1439-1450.

70. Ramani GV, Uber PA, Mehra MR. Chronic heart failure: contemporary diagnosis and management. Mayo Clin Proc. 2010;85(2):180-195.

71. Vargo DL, Kramer WG, Black PK, Smith WB, Serpas T, Brater DC. Bioavailability, pharmacokinetics, and pharmacodynamics of torsemide and furosemide in patients with congestive heart failure. Clin Pharmacol Ther. 1995; 57(6):601-609.

72. Herchuelz A, Derenne F, Deger F, et al. Interaction between nonsteroidal anti-inflammatory drugs and loop diuretics: modulation by sodium balance. J Pharmacol Exp Ther. 1989;248(3):1175-1181.

73. Risler T, Schwab A, Kramer B, Braun N, Erley C. Comparative pharmacokinetics and pharmacodynamics of loop diuretics in renal failure. Cardiology. 1994;84(Suppl 2):155-161.
74. Dormans TP, van Meyel JJ, Gerlag PG, Tan Y, Russel FG, Smits P. Diuretic efficacy of high dose furosemide in severe heart failure: bolus injection versus continuous infusion. $J$ Am CollCardiol. 1996;28(2): 376-382.

75. Sica DA, Gehr TW. Diuretic combinations in refractory oedema states: pharmacokinetic-pharmacodynamic relationships. Clin Pharmacokinet. 1996;30(3):229-249.

76. Linz W, Scholkens BA. A specific B2-bradykinin receptor antagonist HOE 140 abolishes the antihypertrophic effect of ramipril. Br J Pharmacol. 1992;105(4):771-772.

77. McDonald KM, Mock J, D'Aloia A, et al. Bradykinin antagonism inhibits the antigrowth effect of converting enzyme inhibition in the dog myocardium after discrete transmural myocardial necrosis. Circulation. 1995;91(7):2043-2048.

78. Bastien NR, Juneau AV, Ouellette J, Lambert C. Chronic AT1 receptor blockade and angiotensin-converting enzyme (ACE) inhibition in (CHF 146) cardiomyopathic hamsters: effects on cardiac hypertrophy and survival. Cardiovasc Res. 1999;43(1):77-85.

79. Garg R, Yusuf S. Overview of randomized trials of angiotensin-converting enzyme inhibitors on mortality and morbidity in patients with heart failure. JAMA. 1995;273(18):1450-1456. Erratum in: JAMA. 1995; 274(6):462.

80. Packer M, Medina N, Yushak M, Meller J. Hemodynamic patterns of response during long-term captopril therapy for severe chronic heart failure. Circulation. 1983;68(4):803-812.

81. Packer M, Lee WH, Medina N, Yushak M, Kessler PD. Functional renal insufficiency during long-term therapy with captopril and enalapril in severe chronic heart failure. Ann Intern Med. 1987;106(3):346-354.

82. Israili $\mathrm{ZH}$, Hall WD. Cough and angioneuroticedema associated with angiotensin-converting enzyme inhibitor therapy. A review of the literature and pathophysiology. Ann Intern Med. 1992;117(3):234-242.

83. Woo KS, Nicholls MG. High prevalence of persistent cough with angiotensin converting enzyme inhibitors in Chinese. Br J Clin Pharmacol. 1995;40(2):141-144.

84. Roig E, Perez-Villa F, Morales M, et al. Clinical implications of increased plasma angiotensin II despite ACE inhibitor therapy in patients with congestive heart failure. Eur Heart J. 2000;21(1):53-57.

85. Burnier M, Brunner HR. Angiotensin II receptor antagonists. Lancet. 2000;355(9204):637-645.

86. Struthers AD. Angiotensin II receptor antagonists for heart failure. Heart. 1998;80(1):5-6.

87. Lee VC, Rhew DC, Dylan M, Badamgarav E, Braunstein GD, Weingarten SR. Meta-analysis: angiotensin-receptor blockers in chronic heart failure and high risk acute myocardial infarction. Ann Intern Med. 2004;141(9):693-704. Erratum in: Ann Intern Med. 2005; 42(5):391

88. Shibata MC, Tsuyuki RT, Wiebe N. The effects of angiotensin-receptor blockers on mortality and morbidity in heart failure: a systematic review. Int J Clin Pract. 2008;62(9):1397-1402.

89. The Cardiac Insufficiency Bisoprolol Study II (CIBIS-II): a randomised trial. Lancet. 1999;353(9146):9-13.

90. Effect of metoprolol $\mathrm{CR} / \mathrm{XL}$ in chronic heart failure: Metoprolol CR/XL Randomised Intervention Trial in Congestive Heart Failure (MERIT-HF). Lancet. 1999;353(9169):2001-2007.

91. Hjalmarson A, Goldstein S, Fagerberg B, et al. Effects of controlledrelease metoprolol on total mortality, hospitalizations, and well-being in patients with heart failure: the Metoprolol CR/XL Randomized Intervention Trial in congestive heart failure (MERIT-HF). MERIT-HF Study Group. JAMA. 2000;283(10):1295-1302.

92. Packer M, Coats AJ, Fowler MB, et al. Effect of carvedilol on survival in severe chronic heart failure. $N$ Engl J Med. 2001;344(22): 1651-1658.

93. Packer M, Fowler MB, Roecker EB, et al. Effect of carvedilol on the morbidity of patients with severe chronic heart failure: results of the carvedilol prospective randomized cumulative survival (COPERNICUS) study. Circulation. 2002;106(17):2194-2199. 
94. Flather MD, Shibata MC, Coats AJ, et al. Randomized trial to determine the effect of nebivolol on mortality and cardiovascular hospital admission in elderly patients with heart failure (SENIORS). Eur Heart J. 2005; 26(3):215-225.

95. Clinical outcome with enalapril in symptomatic chronic heart failure; a dose comparison. The NETWORK Investigators. Eur Heart J. 1998; 19(3):481-489.

96. Packer M, Poole-Wilson PA, Armstrong PW, et al; for the ATLAS Study Group. Comparative effects of low and high doses of the angiotensin-converting enzyme inhibitor, lisinopril, on morbidity and mortality in chronic heart failure. Circulation. 1999;100(23):2312-2318.

97. Struthers AD. Aldosterone escape during angiotensin-converting enzyme inhibitor therapy in chronic heart failure. J Card Fail. 1996; 2(1):47-54.

98. Farquharson CA, Struthers AD. Spironolactone increases nitric oxide bioactivity, improves endothelial vasodilator dysfunction, and suppresses vascular angiotensin I/angiotensin II conversion in patients with chronic heart failure. Circulation. 2000;101(6):594-597.

99. Pitt B, Zannad F, Remme WJ, et al; Randomized Spironolactone Evaluation Study Investigators. The effect of spironolactone on morbidity and mortality in patients with severe heart failure. $N$ Engl J Med. 1999;341(10):709-717.

100. Pitt B, Remme W, Zannad F, et al; Eplerenone Post-Acute Myocardial Infarction Heart Failure Efficacy and Survival Study Investigators. Eplerenone, a selective aldosterone blocker, in patients with left ventricular dysfunction after myocardial infarction. $N$ Engl $J$ Med. 2003;348(14):1309-1321. Erratum in: N Engl J Med. 2003; 348(22):2271.

101. Zannad F, McMurray JJV, Krum H, et al. Eplerenone in patients with systolic heart failure and mild symptoms. New Eng J Med. 2011; 364(1):11-21.

102. Cohn JN, Archibald DG, Ziesche S, et al. Effect of vasodilator therapy on mortality in chronic congestive heart failure: results of the Veterans Administration Cooperative Study. N Engl J Med. 1986; 314(24):1547-1552.

103. Cohn JN, Johnson G, Ziesche S, et al. A comparison of enalapril with hydralazine-isosorbidedinitrate in the treatment of chronic heart failure. N Engl J Med. 1991;325(6):303-310.

104. Taylor AL, Ziesche S, Yancy C, et al. Combination of isosorbidedinitrate and hydralazine in blacks with heart failure. $N$ Engl $J$ Med. 2004;351(20):2049-2057. Erratum in: N Engl J Med. 2005;352(12):1276

105. Gheorghiade M, Adams KF Jr, Colucci WS. Digoxin in the management of cardiovascular disorders. Circulation. 2004;109(24):2959-2964.

106. Gheorghiade M, Ferguson D. Digoxin: a neurohormonal modulator in heart failure? Circulation. 1991;84(5):2181-2186.

107. The effect of digoxin on mortality and morbidity in patients with heart failure. Digitalis Investigation Group. $N$ Engl $J$ Med. 1997;336(8):525-533.

108. Allman KC, Shaw LJ, Hachamovitch R, Udelson JE. Myocardial viability testing and impact of revascularization on prognosis in patients with coronary artery disease and left ventricular dysfunction: a meta-analysis. J Am CollCardiol. 2002;39(7):1151-1158.

109. Velazquez EJ, Lee KL, O’Connor CM, et al. The rationale and design of the Surgical Treatment for Ischemic Heart Failure (STICH) trial. $J$ Thorac Cardiovasc Surg. 2007;134(6):1540-1547.

110. Di Salvo TG, Acker MA, Dec GW, Byrne JG. Mitral valve surgery in advanced heart failure. J Am CollCardiol. 2010;55(4):271-282.

111. Diodato MD, Moon MR, Pasque MK, et al. Repair of ischemic mitral regurgitation does not increase mortality or improve long-term survival in patients undergoing coronary artery revascularization: a propensity analysis. Ann Thorac Surg. 2004;78(3):794-799.

112. Jones RH, Velazquez EJ, Michler RE, et al; STICH Hypothesis 2 Investigators. Coronary bypass surgery with or without surgical ventricular reconstruction. N Engl J Med. 2009;360(17):1705-1717.
113. Moss AJ, Zareba W, Hall WJ, et al; Multicenter Automatic Defibrillator Implantation Trial II Investigators. Prophylactic implantation of a defibrillator in patients with myocardial infarction and reduced ejection fraction. $N$ Engl J Med. 2002;346(12):877-883.

114. Bardy GH, Lee KL, Mark DB, et al; Sudden Cardiac Death in Heart Failure Trial (SCD-HeFT) Investigators. Amiodarone or an implantable cardio-defibrillator for congestive heart failure. $N$ Engl J Med. 2005;352(3):225-237. Erratum in: $N$ Engl $J$ Med. 2005;352(20):2146.

115. Zipes DP, Camm AJ, Borggrefe M, et al. ACC/AHA/ESC 2006 guidelines for management of patients with ventricular arrhythmias and the prevention of sudden cardiac death: a report of the American College of Cardiology/American Heart Association Task Force and the European Society of Cardiology Committee for Practice Guidelines (Writing Committee to Develop Guidelines for Management of Patients with Ventricular Arrhythmias and the Prevention of Sudden Cardiac Death). J Am CollCardiol. 2006;48(54):e247-e346.

116. Bristow MR, Saxon LA, Boehmer J, et al. Cardiac-resynchronization therapy with or without an implantable defibrillator in advanced chronic heart failure. N Engl J Med. 2004;350(21):2140-2150.

117. Auricchio A, Kloss M, Trautmann SI, Rodner S, Klein H. Exercise performance following cardiac resynchronization therapy in patients with heart failure and ventricular conduction delay. Am J Cardiol. 2002;89(2):198-203.

118. Cleland JG, Daubert JC, Erdmann E, et al. The effect of cardiac resynchronization on morbidity and mortality in heart failure. $N$ Engl J Med. 2005;352(15):1539-1549.

119. McAlister FA, Eskowitz J, Hooton N, et al. Cardiac resynchronization therapy for patients with left ventricular systolic dysfunction: a systematic review. JAMA. 2007;297(22):2502-2514.

120. Beshai JF, Grimm RA, Nagueh SF, et al. Cardiac-resynchronization therapy in heart failure with narrow QRS complexes. $N$ Engl $J$ Med. 2007;357(24):2461-2471.

121. Chung ES, Leon AR, Tavazzi L, et al. Results of the Predictors of Response to CRT (PROSPECT) trial. Circulation. 2008;117(20):2608-2616.

122. Moss AJ, Hall WJ, Cannom DS, et al. Cardiac-resynchronization therapy for the prevention of heart-failure events. $N$ Engl $J$ Med. 2009;361(14):1329-1338.

123. Linde C, Abraham WT, Gold MR, et al. Randomized trial of cardiac resynchronization in mildly symptomatic heart failure patients and in asymptomatic patients with left ventricular dysfunction and previous heart failure symptoms. J Am CollCardiol. 2008;52(23):1834-1843.

124. Daubert C, Gold MR, Abraham WT, et al. Prevention of disease progression by cardiac resynchronization therapy in patients with asymptomatic or mildly symptomatic left ventricular dysfunction: insights from the European cohort of the REVERSE (Resynchronization Reverses Remodeling in Systolic Left Ventricular Dysfunction) trial. J Am CollCardiol. 2009;54(20):1837-1846.

125. Dickstein K, Vardas PE, Auricchio A, et al. 2010 Focused Update of ESC Guidelines on device therapy in heart failure: an update of the 2008 ESC Guidelines for the diagnosis and treatment of acute and chronic heart failure and the 2007 ESC guidelines for cardiac and resynchronization therapy. Developed with the special contribution of the Heart Failure Association and the European Heart Rhythm Association. Eur Heart J. 2010;31(21):2677-2687.

126. Rose EA, Gelijns AC, Moskowitz AJ, et al. Long-term use of a left ventricular assist device for end-stage heart failure. $N$ Engl J Med. 2001;345(20):1435-1443.

127. Slaughter MS, Rogers JG, Milano CA, et al. Advanced heart failure treated with continuous-flow left ventricular assist device. $N$ Engl J Med. 2009;361(23):2241-2251.

128. Stehlik J, Edwards LB, Kucheryavaya AY, et al. The Registry of the International Society for Heart and Lung Transplantation: twentyseventh official adult heart transplant report - 2010. J Heart Lung Transplant. 2010;29(10):1089-1103. 
129. Böhm M, Swedberg K, Komajda M, et al. Heart rate as a risk factor in chronic heart failure (SHIFT): the association between heart rate and outcomes in a randomised placebo-controlled trial. Lancet. 2010;376(9744):886-894.

130. Yusuf S, Pfeffer MA, Swedberg K, et al; CHARM Investigators and Committees. Effects of candesartan in patients with chronic heart failure and preserved left-ventricular ejection fraction: the CHARMPreserved Trial. Lancet. 2003;362(9386):777-781.

131. Massie BM, Carson PE, McMurray JJ, et al; I-PRESERVE Investigators. Irbesartan in patients with heart failure and preserved ejection fraction. NEngl J Med. 2008;359(23):2456-2467.

132. Ahmed A, Rich MW, Fleg JL, et al. Effect of digoxin on morbidity and mortality in diastolic heart failure: the ancillary digitalis investigation group trial. Circulation. 2006;114(5):397-403.
133. Hernandez AF, Hammil BG, O'Connor CM, et al. Clinical effectiveness of beta-blockers in heart failure: findings from the OPTIMIZE-HF (Organized program to Initiate Lifesaving Treatment in Hospitalized Patients with Heart Failure) registry. J Am CollCardiol. 2009;53(2): 184-192.

134. Skhiri M, Hunt SA, Denault AY, Haddad F. Evidence-based management of right heart failure: a systematic review of an empiric field. Rev Esp Cardiol. 2010;63(4):451-471.

135. Clark AL. Origin of symptoms in chronic heart failure. Heart. 2006; 92(1):12-16.

\section{Publish your work in this journal}

Vascular Health and Risk Management is an international, peerreviewed journal of therapeutics and risk management, focusing on concise rapid reporting of clinical studies on the processes involved in the maintenance of vascular health; the monitoring, prevention and treatment of vascular disease and its sequelae; and the involvement of metabolic disorders, particularly diabetes. This journal is indexed on PubMed Central and MedLine. The manuscript management system is completely online and includes a very quick and fair peer-review system, which is all easy to use. Visit http://www.dovepress.com/ testimonials.php to read real quotes from published authors. 